\title{
Punching of RC slabs without transverse reinforcement supported on elongated columns
}

Andri Setiawan

Former PhD candidate, Department of Civil and Environmental Engineering, Imperial College London, London, United Kingdom

\section{Robert L Vollum}

Reader in Concrete Structures, Department of Civil and Environmental Engineering, Imperial College London, London, United Kingdom

\section{Lorenzo Macorini}

Reader in Structural Engineering, Department of Civil and Environmental Engineering, Imperial College London, London, United Kingdom

\section{Bassam A Izzuddin}

Professor of Computational Structural Mechanics, Department of Civil and Environmental Engineering, Imperial College London, London, United Kingdom

\section{Declarations of interest: none}

\begin{abstract}
The paper investigates the influence of support elongation on punching resistance at internal slab column connections without shear reinforcement. Nonlinear finite element analysis (NLFEA) with 3-D solid elements is used to study the influence of column elongation on stress and strain in the slab around the column. Punching failure is shown to be triggered by localised peaks in shear stress around the corners of the support. Significantly, one-way shear is shown to increase the shear resistance of slabs supported on columns with cross sectional dimensions greater than around six times the slab effective depth $(d)$. The common laboratory practice of supporting slabs in punching tests on elongated plates rather than columns is investigated numerically and is found to be reasonable despite uplift occurring in the central region of elongated plates. NLFEA with solid elements gives useful insights into punching failure but nonlinear shell elements are better suited to the practical assessment of slabs in building structures. The disadvantage of conventional nonlinear shell elements is that shear failure can only be detected through post processing of results. To circumvent this, the authors have previously developed a novel modelling approach in which 3-D joint elements are used to connect shell elements located to either side of a punching control perimeter positioned at $0.5 \mathrm{~d}$ from the column face. The joint shear resistance is calculated using the Critical Shear Crack Theory (CSCT) in which punching resistance is related to slab rotation. Based on insights gained using the solid element modelling, this paper extends the use of the joint model to the modelling of punching failure at elongated supports by including oneway joints to model linear shear.
\end{abstract}


Key words: Reinforced concrete design; Punching shear; Elongated supports; Critical Shear Crack Theory; Nonlinear finite element analysis

\section{Introduction}

Notable experimental and theoretical contributions to the understanding of punching failure at elongated columns have been made by Oliveira et al. [1] and Sagaseta et al. [2]. The essence of the problem is illustrated in Fig. 1 which shows that the shear force distribution around concentrically loaded internal columns becomes progressively less uniform as $c / d$ and $c_{\max } / c_{\min }$ increase (where $c$ is the column cross sectional dimension, $d$ is the slab effective depth, $c_{\max }$ is the longer column side and $c_{\min }$ is the shorter column side). The shear force distribution around the control perimeter also depends on the loading arrangement as demonstrated by Sagaseta et al. [2] for slabs with the one-way and two-way loading arrangements depicted in Fig. 2(a) and Fig. 2(b) respectively. Shear resistance is concentrated around the ends of elongated columns but linear (one-way) shear also contributes to shear resistance at walls as illustrated in Fig. 3(a) and Fig. (b).

The need to account for non-uniformity of shear force around supports under concentric loading depends on the support size and the distance from the support face to the control perimeter. This is reflected in the varying design provisions of EC2 [3], ACI 318-14 [4] and MC2010 [5] for punching at large columns. ACI 318-14 and MC2010 position the control perimeter at $0.5 d$ from the column face, which is considered physically representative of punching failure. Consequently, ACI 318-14 and MC2010 include special provisions for reducing the length of the punching control perimeter around large columns due to the non-uniformity of shear force evident in Fig. 1. Conversely, EC2 positions the punching control perimeter at $2 d$ from the column face where the shear force distribution around the control perimeter is relatively uniform under concentric loading as shown by Oliveira et al. [1]. Consequently, EC2 [3] includes no special provisions for reducing the punching control perimeter at large columns. Positioning the control perimeter at $2 d$ also has the advantage that the same concrete design shear resistance can be used for both linear and punching shear.

MC2010 deals with the problem of large columns by limiting the length of the straight segments of the control perimeter to $3 d$ for each edge as illustrated in Fig. 4(a). Following the precedent of Sagaseta et al. [2], this paper depicts the resulting reduced perimeter as $b_{0,3 d}$ in which $3 d$ represents the limiting length of each straight side. Sagaseta et al. [2] assessed the accuracy of the MC2010 approach depicted in Fig. 4(a) by using MC2010 Level of Approximation III (LoA III) to model 33 concentrically loaded internal slab specimens with elongated columns. Within their database, the ratio $c_{\max } / d$ varied between 1.11 and 6.25 and $c_{\max } / c_{\min }$ between 1 and 5 where $c_{\max }$ and $c_{\min }$ are the maximum and minimum column cross section dimensions. Their analysis shows that the reduced control perimeter of MC2010 is reasonable for their considered range of $c_{\max } / d$. This paper extends the analysis of Sagaseta et al. [2] 
to slabs with longer supports $\left(6<c_{\max } / d<10\right)$ where nonlinear analysis with 3-D solid elements is used to show that linear shear makes a non-negligible contribution to shear resistance. Subsequently, parametric studies are carried out with NLFEA to investigate punching failure in slabs with $c_{\max } / d$ between 6 and 10 for which very few test data are available. These studies are used to refine a joint model proposed by Setiawan et al. [6] in which 3-D joint elements are used to simulate punching failure in slabs meshed with conventional nonlinear layered-shell elements. Two-way joint shear resistance is calculated using the Critical Shear Crack Theory (CSCT) of Muttoni [7]. In the refined joint model, one-way shear joint elements are positioned along the parts of the control perimeter neglected by MC2010 as shown in Fig. 4(b). It is pertinent to note here that the punching provisions in the draft revision to EC2 [8], due for publication in 2023, are based on a closed form formulation of the CSCT utilised in this research. Furthermore, the basic punching control perimeter is positioned at $0.5 d$ from the column face in the draft revision to EC2.

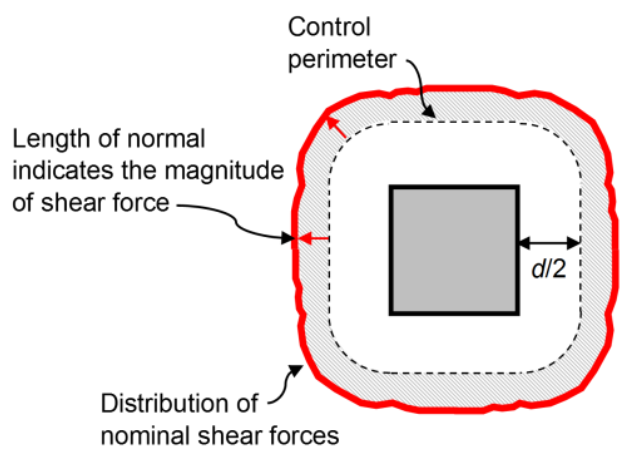

(a)

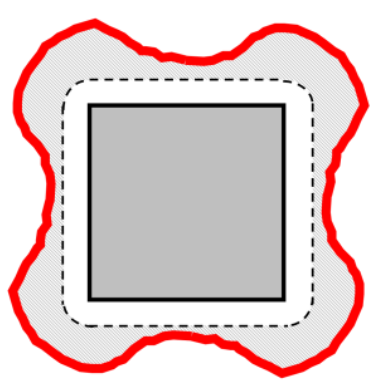

(b)

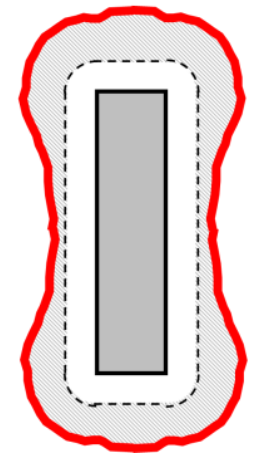

(c)

Figure 1. Distribution of nominal shear forces along control perimeter at $0.5 d$ from the column face for internal columns with (a) $c / d=1$; (b) $c / d=4$; (c) $c_{\max } / c_{\min }=4$ and $c_{\min } / d=1.24$ (adapted from [2]).

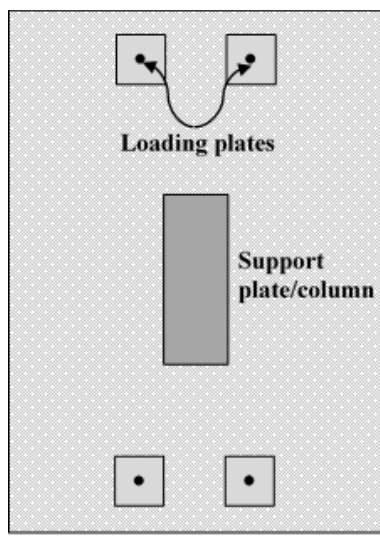

Type A

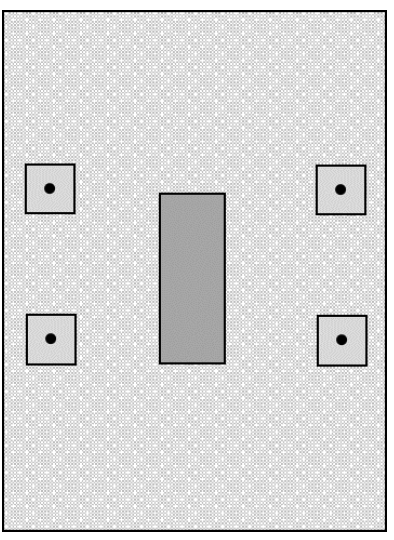

Type B

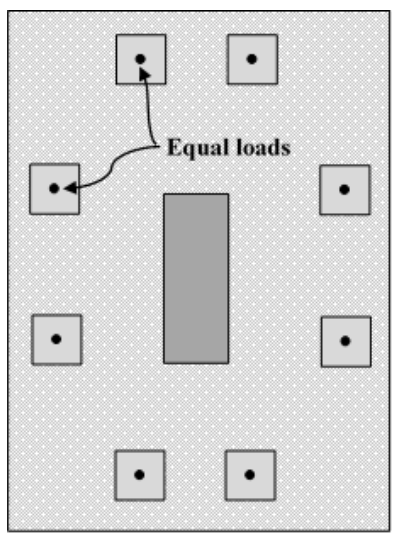

Type C

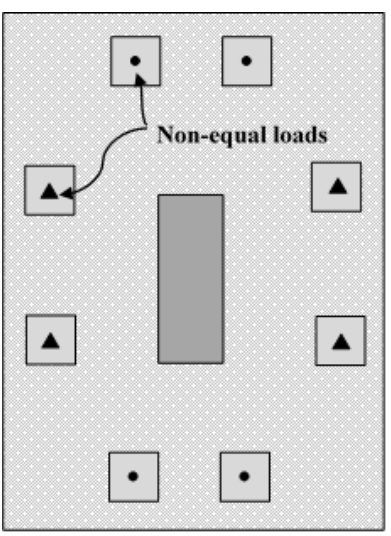

Type D

(a)

(b)

Figure 2. Typical test setups for isolated slabs supported on elongated column loaded in: (a) one-way bending; (b) two-way bending. 


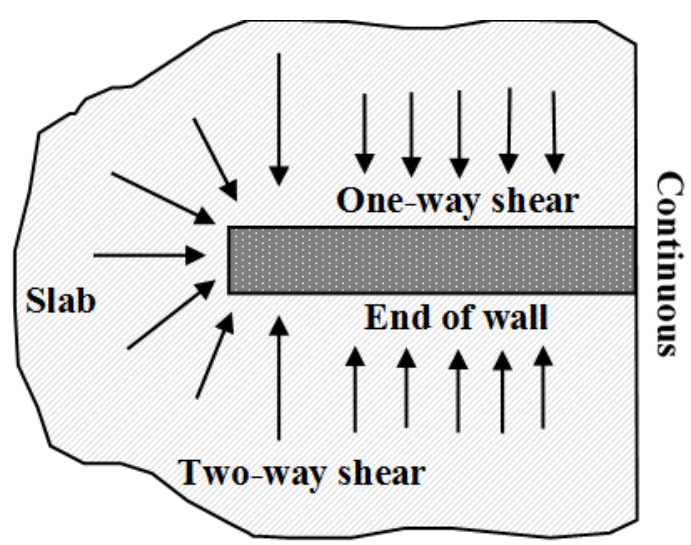

(a)

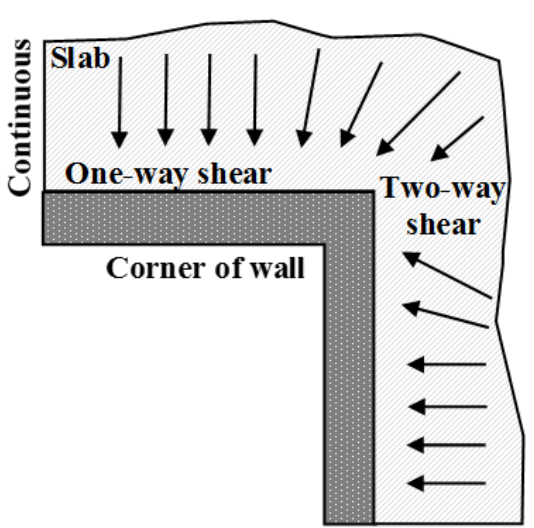

(b)

Continuous

Figure 3. One- and two-way shear forces transferred from the slab to the support at: (a) end of wall; (b) corner of wall.

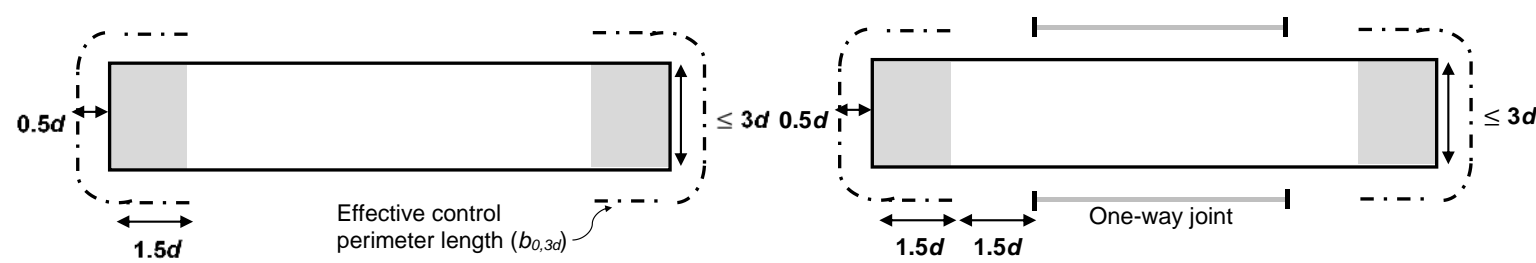

(a)

(b)

Figure 4. Estimation of effective control perimeter length $b_{0,3 d}$ for slabs supported on large or elongated column according to: (a) MC2010 [5]; (b) proposed numerical model.

\section{Nonlinear finite element analysis using 3-D solid elements}

NLFEA with 3-D solid elements was carried out using ATENA [9] to study the failure mechanism of slabs L3c, L4c and L5c of Oliveira et al. [1], having $c_{\max } / c_{\min }$ equal to 3, 4 and 5 respectively as well as slabs OC13 and OC15 of Teng et al. [10]. The latter were chosen since OC15 with $c_{\max } / d=8.77$ has the most elongated support known to the authors. The plan dimensions and loading arrangements of these slabs are shown in Fig. 5. Other details required for modelling are given in Table 1. All the slabs were loaded with eight equal point loads.

The main objective of the NLFEA with solid elements presented in this paper is to gain insights into the contribution of one-way shear to the overall shear resistance of slabs supported on elongated supports. These insights are subsequently used to refine the Joint-Shell Punching Model (JSPM) previously developed by the authors [6]. Parametric studies are also carried out with ATENA in order to fill gaps in the experimental database which is used subsequently to validate the refined JSPM. 


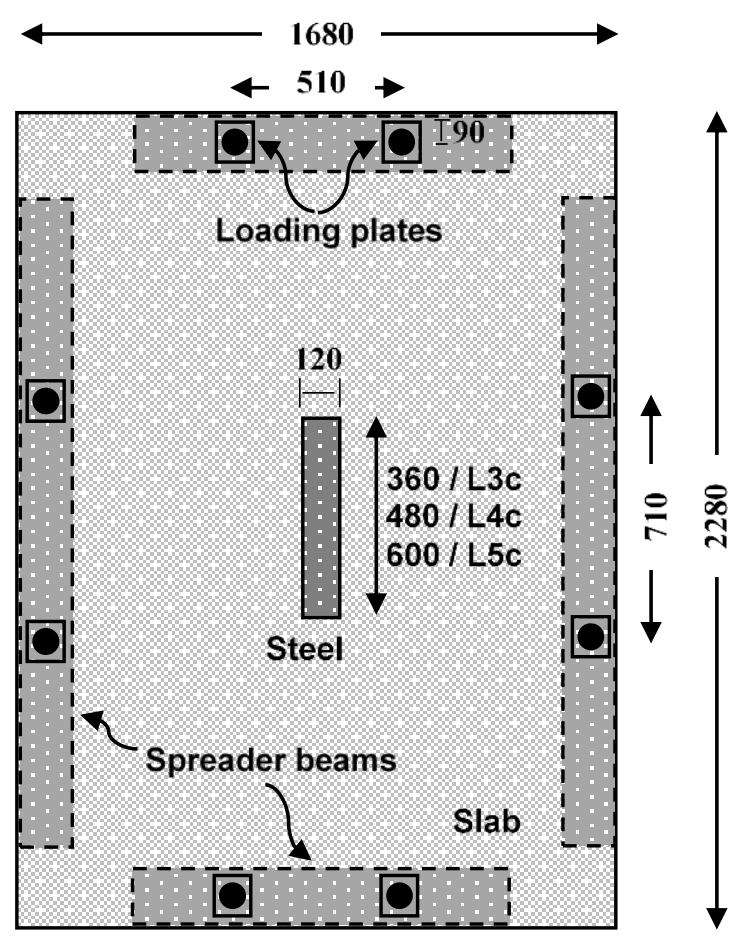

(a)

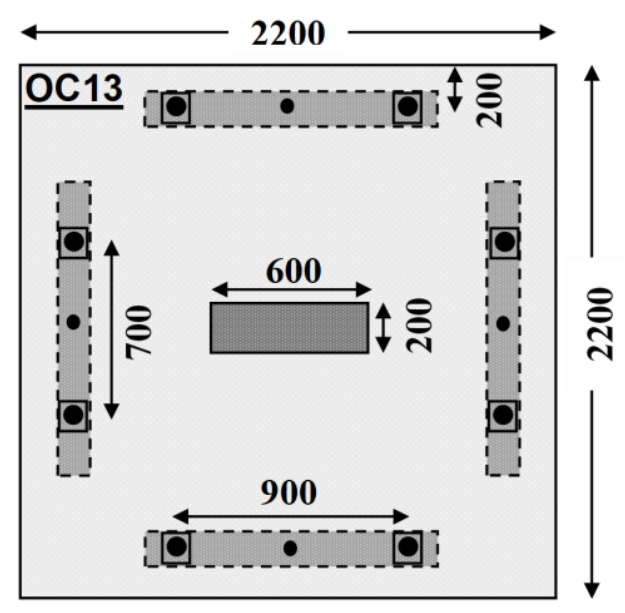

(b)

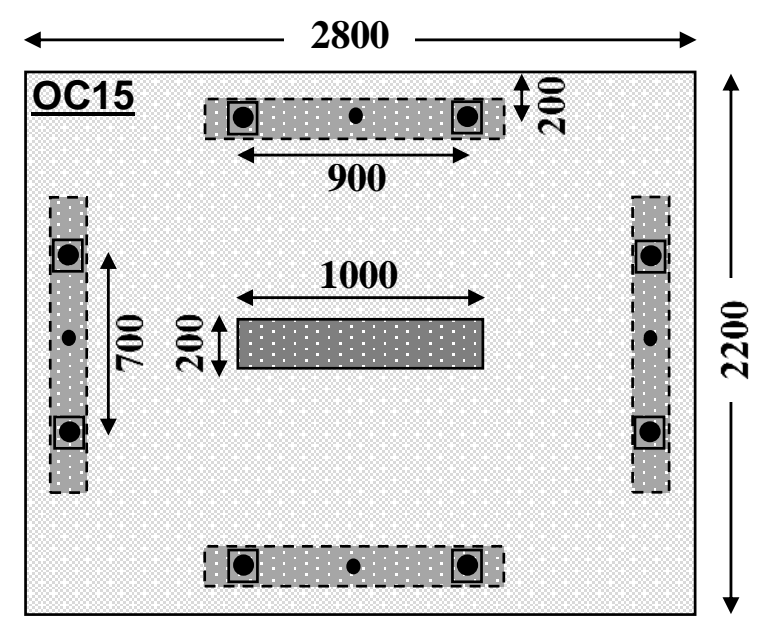

(c)

Figure 5. Illustration of experimental test setup used by: (a) Oliveira et al. [1]; (b),(c) Teng et al. [10] for OC13 and OC15, respectively (all units in mm). 
Table 1. Summary of properties of slab specimens with elongated column.

\begin{tabular}{|c|c|c|c|c|c|c|c|c|c|c|c|c|}
\hline Slab & Source & $\begin{array}{c}\text { Slab } \\
\text { thick } \\
\text {-ness } \\
(\mathbf{m m})\end{array}$ & $\begin{array}{l}c_{\max } \\
(\mathbf{m m})\end{array}$ & $\begin{array}{c}\boldsymbol{c}_{\min } \\
(\mathbf{m m})\end{array}$ & $\begin{array}{l}c_{\max } \\
/ c_{\min }\end{array}$ & $\underset{(\mathbf{m m})}{d}$ & $\begin{array}{l}c_{\max } \\
/ \boldsymbol{d}\end{array}$ & $\begin{array}{c}\boldsymbol{f}_{c}^{\prime} \\
(\mathbf{M P a})\end{array}$ & $\begin{array}{c}\boldsymbol{d}_{\boldsymbol{g}} \\
(\mathbf{m m})\end{array}$ & $\begin{array}{c}\boldsymbol{f}_{\boldsymbol{y}} \\
(\mathbf{M P a})\end{array}$ & $\begin{array}{c}\boldsymbol{\rho}_{x} \\
(\%)\end{array}$ & $\begin{array}{c}\rho_{y} \\
(\%)\end{array}$ \\
\hline L3c & \multirow{3}{*}{$\begin{array}{l}\text { Oliveira } \\
\text { et al. [1] }\end{array}$} & \multirow{3}{*}{130} & 360 & 120 & 3 & 106 & 3.40 & 54 & 16 & 749 & 1.06 & 1.03 \\
\hline $\mathrm{L} 4 \mathrm{c}$ & & & 480 & 120 & 4 & 107 & 4.49 & 56 & 16 & 749 & 1.06 & 1.03 \\
\hline L5c & & & 600 & 120 & 5 & 109 & 5.50 & 63 & 16 & 749 & 1.06 & 1.03 \\
\hline OC13 & \multirow{2}{*}{$\begin{array}{l}\text { Teng et } \\
\text { al. [10] }\end{array}$} & \multirow{2}{*}{150} & 600 & 200 & 3 & 114 & 5.26 & 35.81 & 20 & 452.5 & 1.47 & 1.47 \\
\hline OC15 & & & 1000 & 200 & 5 & 114 & 8.77 & 40.15 & 20 & 452.5 & 1.47 & 1.47 \\
\hline
\end{tabular}

Note: $d_{g}=$ aggregate size; $f_{y}=$ reinforcement yield stress

\subsection{Material modelling in ATENA and model calibration}

A smeared crack approach was used in ATENA [9] in conjunction with concrete material model CC3DNonLinCementitious2 which combines constitutive models for tensile (fracture) and compressive (plastic) behaviour. Triaxial behaviour of concrete in compression is modelled using the MenetreyWillam failure surface [11] which is expressed in terms of three independent stress invariants: hydrostatic stress, deviatoric stress, and deviatoric polar angle. A detailed description of the model is provided by Cervenka et al. [9] so only essential details are given here. The hardening/softening law [9] is based on the uniaxial compressive test. The ascending part of the law expresses the compressive stress $\sigma$ in terms of an equivalent plastic strain $\varepsilon_{e q}^{p}$ as follows:

$$
\sigma=f_{c 0}+\left(f_{c}^{\prime}-f_{c 0}\right) \sqrt{1-\left(\frac{\varepsilon_{c}^{p}-\varepsilon_{e q}^{p}}{\varepsilon_{c}^{p}}\right)^{2}}
$$

where $f_{c 0}$ is the stress at onset of concrete nonlinear behaviour in compression and $\varepsilon_{c}^{p}$ is the plastic strain at the uniaxial concrete compressive strength $\left(f_{c}^{\prime}\right)$.

After cracking, the concrete compressive strength is reduced similarly to the Modified Compression Field Theory [12] with the strength reduction based on:

$$
f_{c^{\prime}}^{e f}=r_{c} f_{c}^{\prime}, r_{c}=\frac{1}{0.8+170 \varepsilon_{1}}, r_{c}^{l i m} \leq r_{c} \leq 1.0
$$

where $r_{c}^{l i m}$ is a user defined parameter that limits the maximum possible reduction in compressive strength. In ATENA, $\varepsilon_{1}$ is taken as the largest maximal fracturing strain [9]. 
In order to reduce mesh size sensitivity during compressive strain localisation, the descending branch of the compressive response is reduced linearly to zero at a displacement $w_{d}$ as proposed by Van Mier [13]. The displacement $w_{d}$ is the product of the equivalent plastic strain and a length scale parameter equal to the projection of the element size into the direction of minimal principal stresses [9]. This approach is equivalent to basing the softening branch on the compressive fracture energy. The Rankine tensile failure criterion was used with a fracture energy based exponential softening function. ATENA gives the option of using either a fixed- or rotating-crack model. The latter was used in this study since it produced more accurate load-rotation responses with the former tending to overestimate stiffness. Use of the rotating crack model is also more objective in ATENA since it avoids the need to choose an arbitrary Shear Factor (SF) in the fixed crack model.

The NLFEA modelling procedure used in this paper was calibrated in a previous study [14] using eight internal punching specimens with square supports (four with varying flexural reinforcement ratios from the PG-series of Guandalini et al. [15] and four with non-symmetric reinforcement arrangement from the PT-series of Sagaseta et al. [16]). Linear order (8-noded) brick elements were used to model the concrete slab since calibration studies showed them to perform significantly better than quadratic elements [17]. Advantage was taken of symmetry to model one quarter of each slab. Based on initial studies the calibration was carried out using a gradated mesh in which cubic elements with side length $m=h / 10$ (where $h$ is the slab thickness) were used to model the slab within a distance of $2 d$ from the column face. A coarser mesh, on plan, with element sides measuring $2 m \times m \times m$ (i.e. length $\times$ width $\times$ thickness), $m \times 2 m \times m$, or $2 m \times 2 m \times m$ was used elsewhere as illustrated for a slab with elongated support in Fig. 6. Support and loading plates were modelled using linear tetrahedral (4-noded) elements with elastic steel material. Reinforcement bars were modelled as embedded using 1D 2-noded linear truss elements assuming perfect bond between reinforcement and concrete. The reinforcement stress strain response was modelled as bilinear with strain hardening modulus of $0.2 \mathrm{MPa}$. All elements are integrated using a Gauss integration scheme that ensures $n(n-1)$ order accuracy, where $n$ is degree of the polynomial used to approximate the integrated function [9]. For the adopted linear order elements, 1,1 , and 8 gauss integration sampling points are used for truss, tetrahedral, and hexahedral elements respectively. Further details are given by Cervenka et al. [9]. Loading plates were connected to the slab through master-slave constraints. To ensure a compatible master-slave constraint relationship, a finer mesh was used for the loading plates (slave) than for the concrete slab (master) [9].

The equilibrium path under vertical loads was obtained using an arc-length control procedure. The convergence tolerances were set at $1 \%$ for displacement, residual force, and absolute residual force error and $0.01 \%$ for energy error with all errors defined as in [9]. These are the default tolerances in ATENA. The same tolerances were used by Setiawan in references [6, 14 and 17] which incorrectly report the energy error tolerance as $0.1 \%$. These criteria are all used simultaneously within ATENA 
with the most onerous governing. The relation between the total number of iterations and all four convergence criteria varies dependent on the degree of nonlinearity in the model. For example, the total number of iterations required for convergence tends to increase significantly at first cracking and near failure. The governing of the four adopted criteria is usually the absolute residual force error. The finally adopted modelling input parameters from the calibration study are summarised in Table 1. As described in [14], the calibration study accurately captured the punching resistance (with mean and covariance of test/predicted resistances equal to 0.983 and 0.075 ) and corresponding maximum slab rotation (with mean and covariance of test/predicted equal to 0.964 and 0.112 ).

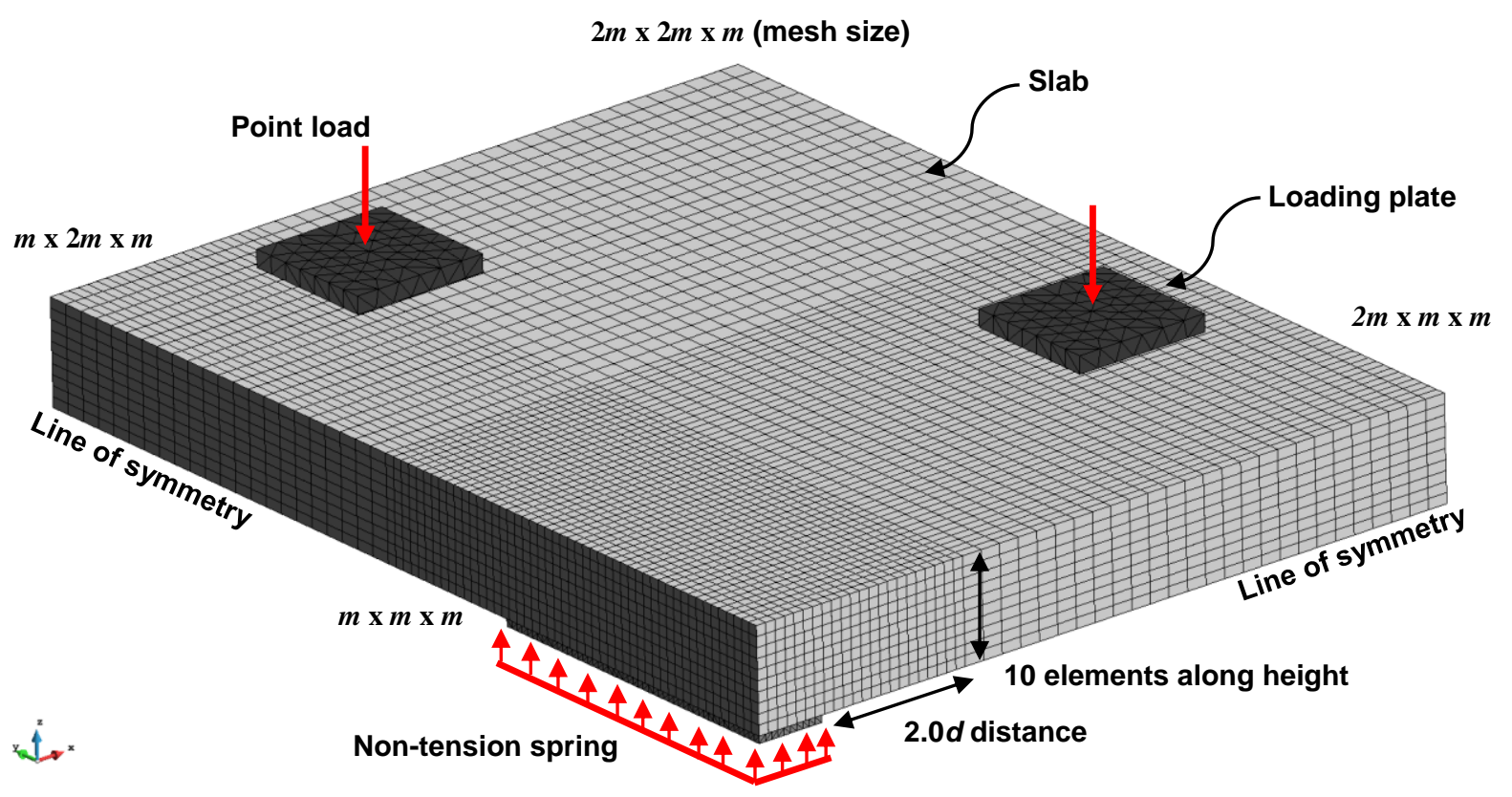

Figure 6. Mesh configuration and boundary conditions of typical quarter slab model in ATENA.

\subsection{Strain-based failure criterion}

Fig. 7 compares the measured and predicted load rotation responses of slabs PT22 and PT31 from the calibration study. These slabs of Sagaseta et al. [16] measured $3 \mathrm{~m}$ square on plan by $250 \mathrm{~mm}$ thick and were supported on $260 \mathrm{~mm}$ square steel plates. The slabs were symmetrically reinforced with flexural reinforcement ratios $\left(\rho_{\text {top }}\right)$ of $0.82 \%$ and $1.48 \%$ for slabs PT22 and PT31 respectively. Due to symmetry, only one quarter of each slab was modelled. As illustrated in Fig. 7, the calibrated NLFEA with ATENA captures the measured load displacement response of the slabs used in the calibration study well. Fig. 7 also shows the variation in the predicted strain in the slab soffit normal to the control perimeter at the mid-side (centre) and corner of the support. These strains, which are extracted at element nodes located on or immediately adjacent to the control perimeter, are seen to drop abruptly to zero at the peak load as observed experimentally by Ferreira et al. [20] amongst others. Broms [21] has previously suggested that punching failure occurs when the "compression zone adjacent to the column collapses". Making reference to experimental results, Broms hypothesises that punching failure occurs 
as the radial compressive strain in the slab soffit adjacent to the column approaches zero. For modelling reasons, he proposed an empirical failure criterion in which punching failure is assumed to occur at a limiting tangential strain corresponding to the point at which the radial compressive strain in the slab soffit adjacent to the column starts to reduce. Broms [21] relates the limiting tangential compressive strain to member depth as well as concrete brittleness, which reduces with increasing compressive strength. Significantly, experimental evidence from the punching tests of Hallgren [22] with high strength concrete and Guandalini et al. [15] (125 mm, $250 \mathrm{~mm}$ and $500 \mathrm{~mm}$ thick slabs) suggests that such modifications are unnecessary for a radial strain-based failure criterion. Consequently, it is proposed that the NLFEA punching resistance is taken as the load at which the radial compressive strain in the slab soffit at $0.5 d$ from the column face first drops to zero or the peak load prior to that if greater.

Table 2. Summary of material parameters and numerical input for NLFEA in ATENA.

\begin{tabular}{|c|c|c|}
\hline No. & Parameter & Value/Reference \\
\hline & Concrete constitutive model & \\
\hline A1 & Concrete elastic modulus & Model Code 2010 [5] \\
\hline $\mathrm{A} 2$ & Fracture energy & Model Code 2010 [5] \\
\hline A3 & Concrete tensile strength & Model Code 2010 [5] \\
\hline A4 & Smeared crack model & Fully-rotating crack \\
\hline A5 & Critical compressive displacement $\mathrm{w}_{\mathrm{d}}$ & $0.5 \mathrm{~mm}$ \\
\hline A6 & $\begin{array}{l}\text { Limit of compressive strength reduction due to } \\
\text { cracking (MCFT) }\end{array}$ & $0.8 f_{c}^{\prime}$ \\
\hline A7 & $\begin{array}{l}\text { Eccentricity (defining the shape of the failure } \\
\text { surface) }\end{array}$ & 0.52 \\
\hline \multirow[t]{2}{*}{ A8 } & Volume dilatation plastic factor & 0 \\
\hline & Reinforcement bar model & \\
\hline B1 & Stress-strain relationship & $\begin{array}{l}\text { Bilinear with strain hardening } \\
\text { modulus of } 0.2 \mathrm{MPa}\end{array}$ \\
\hline \multirow[t]{2}{*}{ B2 } & Bond-slip model & Perfect bond \\
\hline & Loading procedure and convergence criteria & \\
\hline $\mathrm{C} 1$ & Loading procedure & Static (force-controlled) \\
\hline $\mathrm{C} 2$ & Solution procedure & Arc-length method \\
\hline $\mathrm{C} 3$ & $\begin{array}{l}\text { Convergence criteria for displacement, residual } \\
\text { force, and absolute residual force error }\end{array}$ & $1 \%$ \\
\hline \multirow[t]{2}{*}{$\mathrm{C} 4$} & Convergence criterion for energy error & $0.01 \%$ \\
\hline & Mesh properties & \\
\hline D1 & $\overline{\text { Mesh size (finest) }}$ & $\begin{array}{l}m \times m \times m m m(10 \text { elements along } \\
\text { height) }\end{array}$ \\
\hline D2 & Mesh element for concrete slab & 8-noded hexahedral (linear) \\
\hline D3 & Mesh element for loading apparatus & 4-noded tetrahedral (linear) \\
\hline D4 & Mesh element for reinforcement bar & 2-noded truss element (embedded) \\
\hline
\end{tabular}



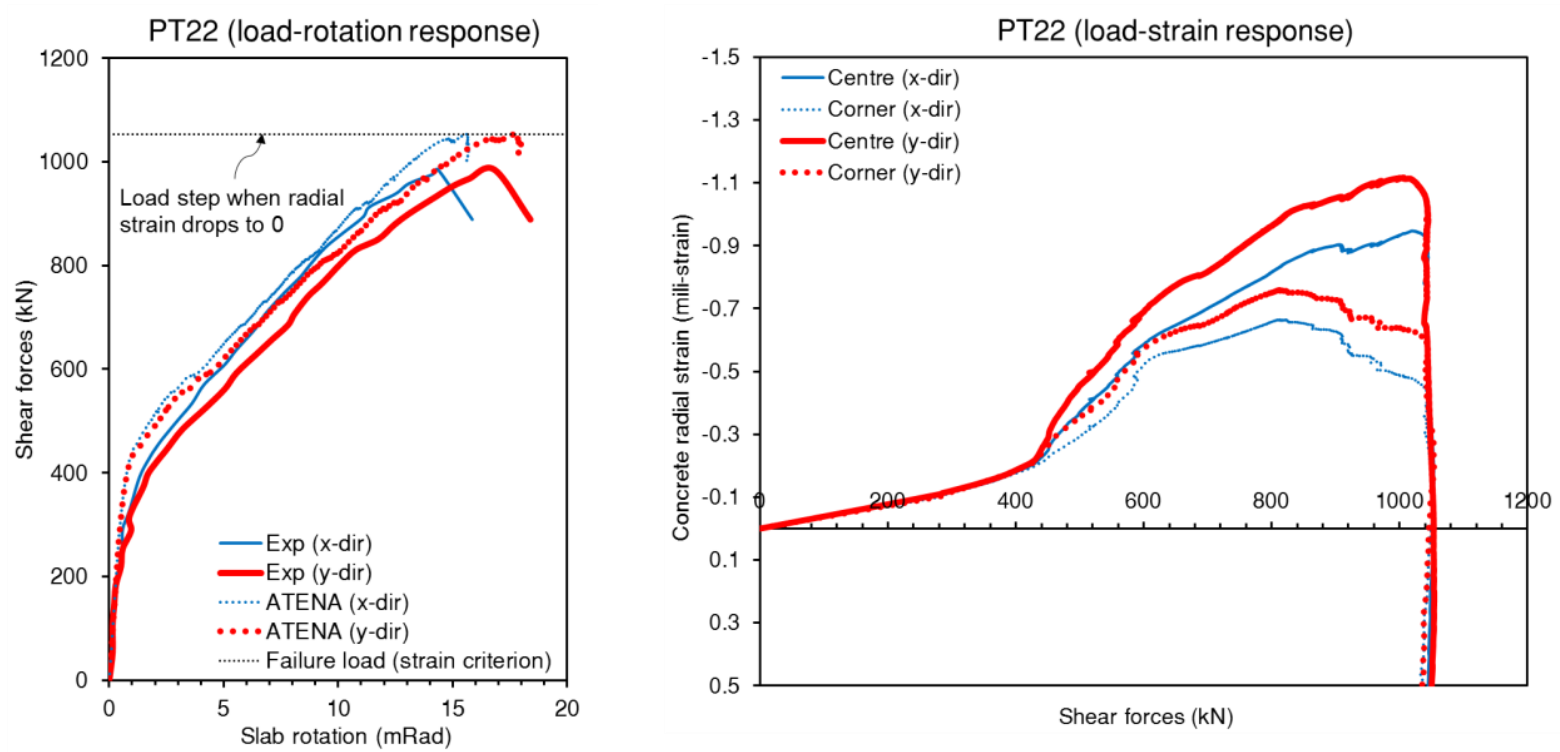

(a)
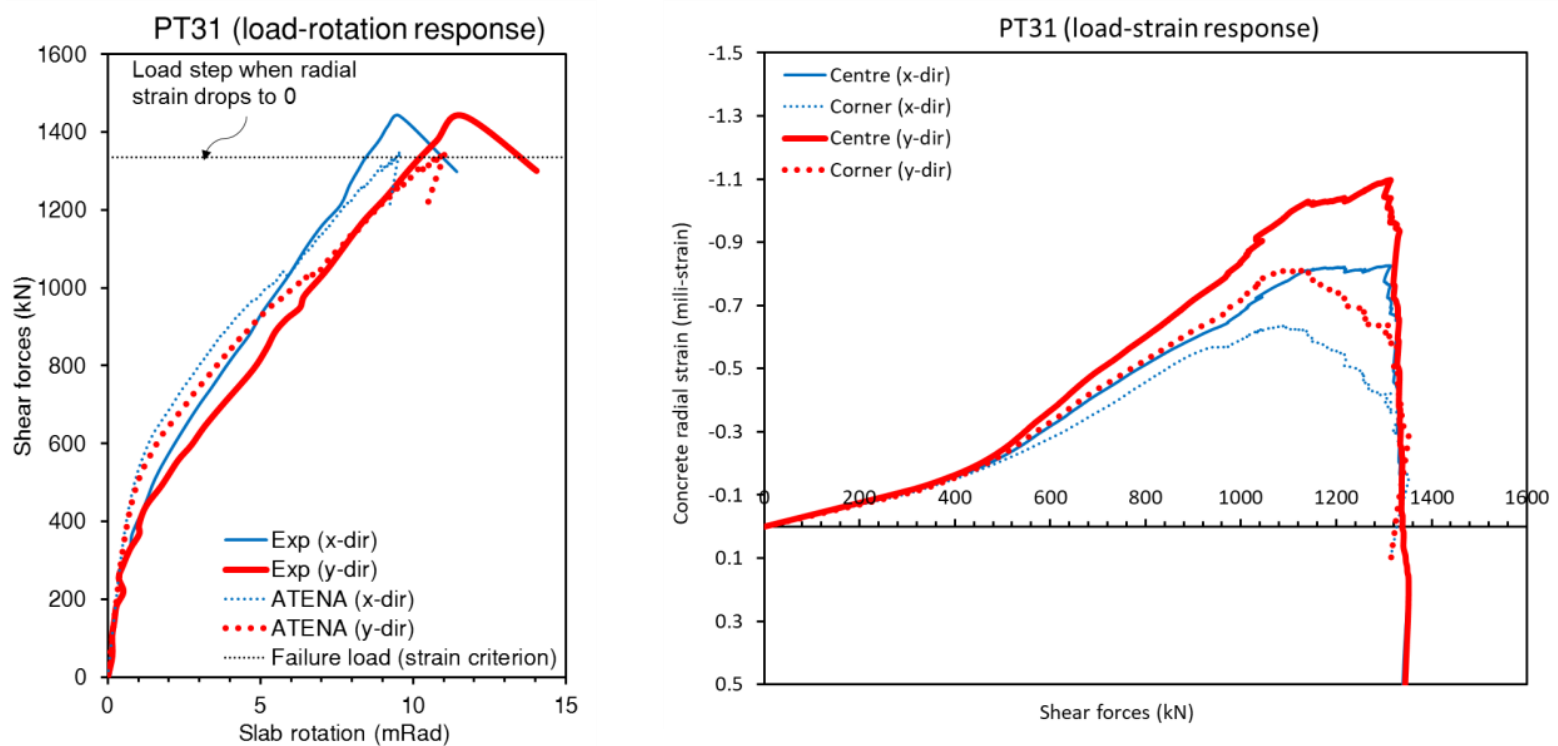

(b)

Figure 7. Load-rotation response along with the plot of radial concrete strain at $0.5 d$ from the column face for slabs: (a) PT22 $\left(\rho_{\text {top }}=0.82 \%\right)$; and (b) PT31 $\left(\rho_{\text {top }}=1.48 \%\right)$ [16].

It is considered unnecessary to modify the strain limit to account for concrete brittleness or the size effect since these are already accounted for in both the failure criterion and the NLFEA as shown in the calibration study [14]. In ATENA, strains were monitored at element nodes in the slab soffit. Numerical studies showed the radial strain to be fairly uniform along the shorter side of a control perimeter at $0.5 \mathrm{~d}$ from the column face. Consequently, it is proposed that punching failure can be related to radial strain in the slab soffit at the slab centreline. 


\subsection{Modelling of slabs with elongated supports with ATENA}

The slabs with elongated supports described in Table 1 were modelled with ATENA using the procedure determined in the calibration study [14] which is summarised in Section 2.1 and Table 2. Comparisons are made with measured failure loads and deflections where available. The previously described strain-based failure criterion was used since otherwise the ATENA analysis overestimated the measured failure load as discussed in (1) below. At the local level (2), the predicted crack patterns are examined as well as the distribution of shear force around the control perimeter which informs the development of the proposed refined joint model.

Nonlinear spring elements with high compressive but very low tensile stiffness (1/1000 of compressive stiffness) were used to simulate uplift of the slab over the central region of steel support plates. As shown in Fig. 6, the support was modelled as a thin steel plate of thickness $5 \mathrm{~mm}$ supported on vertical springs. The steel plate was connected to the slab using a master-slave boundary condition in which the master and slave nodes shared the same degrees of freedom in all directions. Spring elements were placed on the underside of the steel support plate to enable uplift of the slab over the central region of the support. The springs were placed underneath the steel plate, rather than between the slab and plate, in order to simplify the construction of the FEM in ATENA. The use of vertical springs under the support plate is a simplification which neglects the influence of lateral restraint provided by friction. However, this simplification does not significantly affect the calculated failure load as shown in Section 2.4 where no significant difference in punching resistance is found for slabs with fully clamped supports and vertical spring supports.

The mesh discretisation adopted in the initial calibration study can lead to a minimum element size that is less than the maximum aggregate size for thin slabs including those of Oliveira et al. [1] and Teng and al. [10] which are considered in this paper. The significance of this is open to debate and merits further investigation. For example, the authoritative Dutch RTD Guidelines [18] state that there is no minimum element size requirement. On the other hand, Genikomsou and Polak [19] argue that the minimum element size should be greater than the maximum aggregate size to avoid size effects introduced by "equations failing to converge numerically". The influence of modelling the slab with 5, 7 and 10 elements through its thickness is illustrated in Fig. 8 for PT22 [16], used in the initial calibration, and OC13 [10]. The gradation of element size within the mesh was as shown in Fig. 6 but with the number of through thickness elements reduced accordingly. The meshing of the loading and support plates was the same in all analyses. In the case of 10 elements through the slab thickness the minimum element size was slightly less than the maximum aggregate size for the slabs of Oliveira et al. [1] and Teng and al. [10] but not PT22. As shown in Fig. 8 increasing the element size tended to soften the load deformation response above $50-60 \%$ of the maximum applied load without significantly changing the load at the maximum applied displacements. In the case of slab OC13, the analyses were 
terminated prior to their conclusion since the radial compressive strain in the slab soffit around the column had clearly gone into tension indicating unrealistic redistribution of shear stress around the control perimeter. Fig. 8(b) also indicates the failure load obtained using the strain-based failure criterion described in the previous section which was adopted in the paper for slabs with elongated supports. Fig. 8(b) indicates that the failure load obtained using this criterion is mesh sensitive with reasonable predictions of failure load being obtained for the considered specimens when either 7 or 10 elements are used through the slab thickness. Based on Fig. 8, the adoption of 10 elements through the slab thickness is considered reasonable for the slabs of Oliveira et al. [1] and Teng et al. [10].

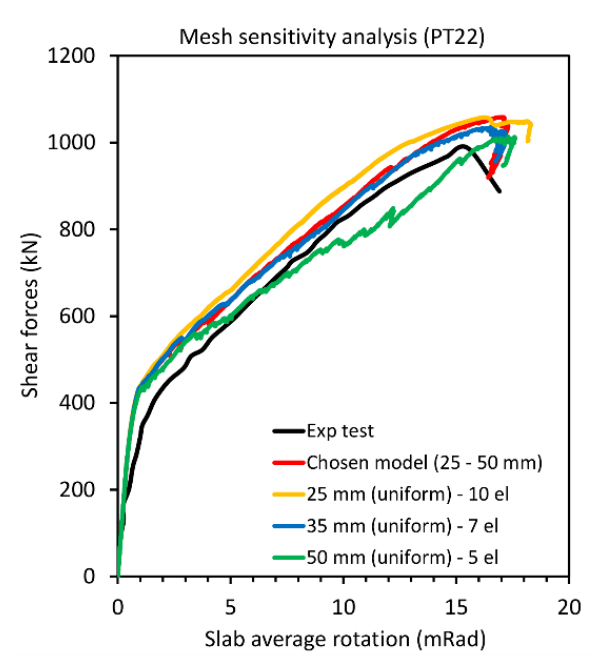

(a)

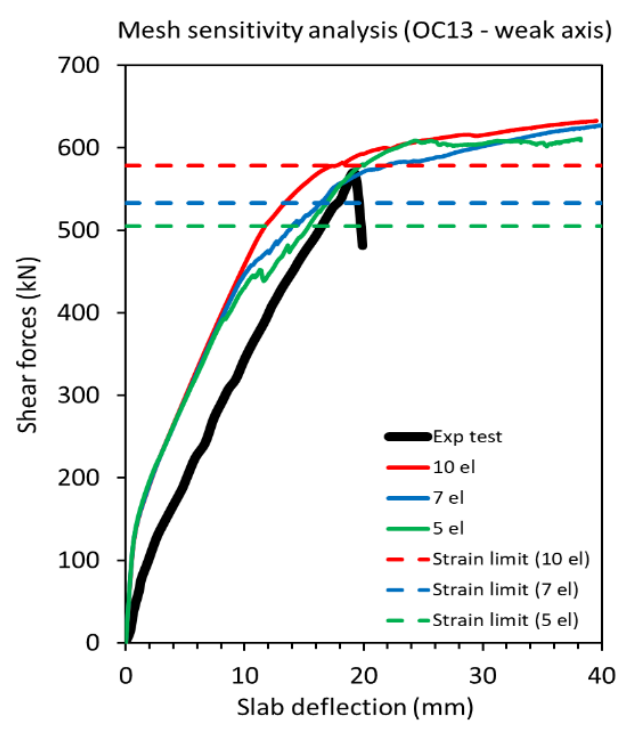

(b)

Figure 8. Influence of element size on NLFEA load displacement response for specimens: a) PT22 [16] and b) OC13 [10].

(1) Global response and determination of failure

Fig. 9 shows predicted load-deflection responses and experimental ones where available. In the slabs of Oliveira et al. [1], for which experimental deflections are unavailable, deflections are shown at the centre of the shorter slab edge. In the slabs of Teng et al. [10], measured and predicted deflections are shown at a perpendicular distance of $100 \mathrm{~mm}$ from the centre of both the long (strong axis) and short (weak axis) slab edges. With the exception of slab OC15, ATENA does not capture either the observed failure load or the sudden drop in resistance following failure. Interestingly, Milligan and Polak [23] obtained plateau like responses when using solid elements in ABAQUS to model punching failure of a slab supported on a long wall. To circumvent this, Milligan and Polak identified punching failure from crack patterns and contours of maximum principal tensile strain [23]. Based on Fig. 7 which is representative, and experimental observations [15, 20-22, 24], this study assumes that punching failure 
occurs when the radial compressive strain in the slab soffit, at the slab centreline, first drops to zero at a distance of $0.5 \mathrm{~d}$ from the column face. Fig. 9 shows that adoption of this strain-based failure criterion gives reasonable predictions of measured failure loads for all the considered specimens except L3c where the failure load is overestimated by around 15\%. It is pertinent to note that the strain-based failure criterion gives reasonable predictions of the peak resistance of slabs OC13 and OC15 (see Fig. 9(d, e)), which were $150 \mathrm{~mm}$ thick, as well as slabs PT22 and PT31 (see Fig. 7) which were $250 \mathrm{~mm}$ thick. The compressive strengths of OC13 \& OC15 were 35.81 and 40.15 MPa respectively compared with 67.0 MPa and 66.3 MPa for slabs PT22 and PT31 respectively. These results indicate that the adopted strain criterion is objective and does not need to be adjusted for concrete brittleness or slab depth. However, its limit of applicability should be limited to the analysed slabs for now. Overall, the accuracy of the strain-based predictions is considered good given the complexity of the failure mechanism.

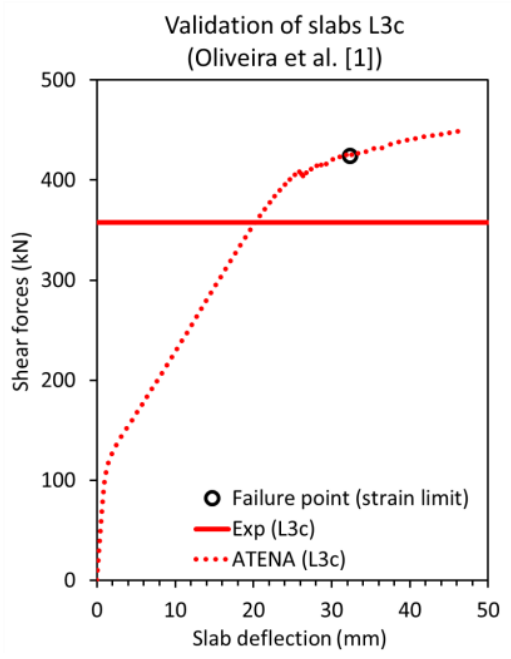

(a)

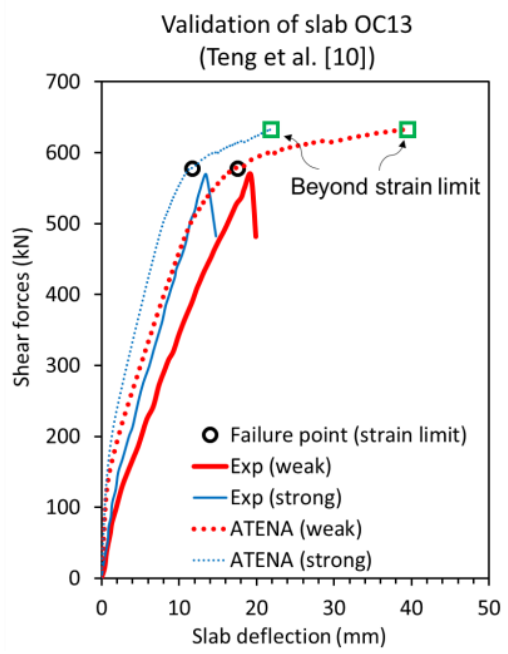

(d)

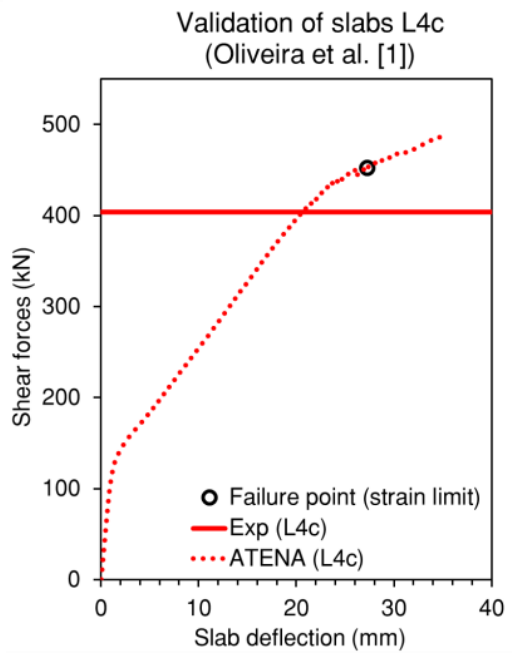

(b)

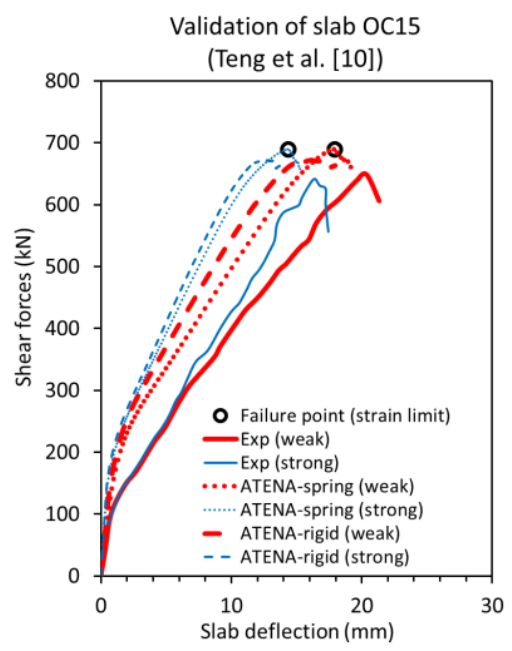

(e)

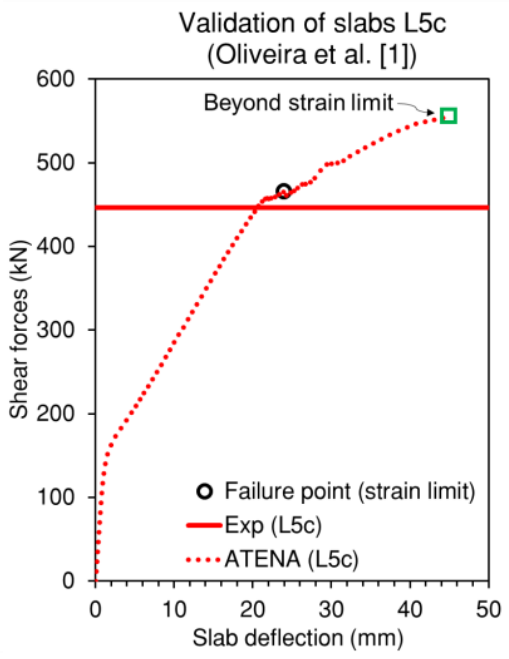

(c)

Figure 9. Comparison of measured vs predicted load-deflection response and failure load of slabs: (a) L3c; (b) L4c; (c) L5c of Oliveira et al. [1]; (d) OC13; and (e) OC15 of Teng et al. [10]. 
Fig. 9(e) also indicates that the punching resistance of OC15 is not significantly influenced by changing the support condition from rigid to springs with high compressive but very low tensile stiffness.

(2) Local behaviour

Crack patterns: Fig. 10 shows crack patterns at failure for slabs L5c and OC15. These slabs were chosen because they are the slabs with the longest support from each test series. Only cracks wider than $0.1 \mathrm{~mm}$ are shown. Radial cracks predominate near the column corner while tangential cracks dominate along the long side of the support. This kind of behaviour becomes more pronounced with increasing support length and reflects the transition from two-way shear around $b_{0,3 d}$ to linear shear along the longer column sides. The edge views along the planes of symmetry show that distinct diagonal punching cracks formed at the centre of the shorter support side whereas flexural-shear cracks formed along the longer side (slab OC15). Also shown in Fig. 10 are contour diagrams depicting the reduction in peak concrete compressive strength $\left(f_{c}\right)$, due to transverse tensile strain, at peak load. The contours are a measure of concrete damage since the greatest reduction in compressive strength occurs where cracks are widest. The localisation of punching failure is clearest in Fig. 11 which shows principal tensile strain at the underside of slab L5c as well as its deformed shape. The side views in Figs. 10 and $\mathbf{1 1}$ show the first row of elements along the slab centreline in each orthogonal direction. Tensile strain is seen to develop in the bottom surface of the slab (compressive region) at failure owing to reversal of radial strain from compression to tension. This behaviour is consistent with the experimental observations of Ferreira et al. [20]. Tensile strain only developed close to the end of the support indicating that punching failure developed locally as observed experimentally by Oliveira et al. [1]. Further evidence of the localised nature of the punching failure is provided by the side-view deformations in Fig. 11 which show that out of plane shear deformation only developed along the shorter support side. Although not shown here, the response of the other slabs was similar. 

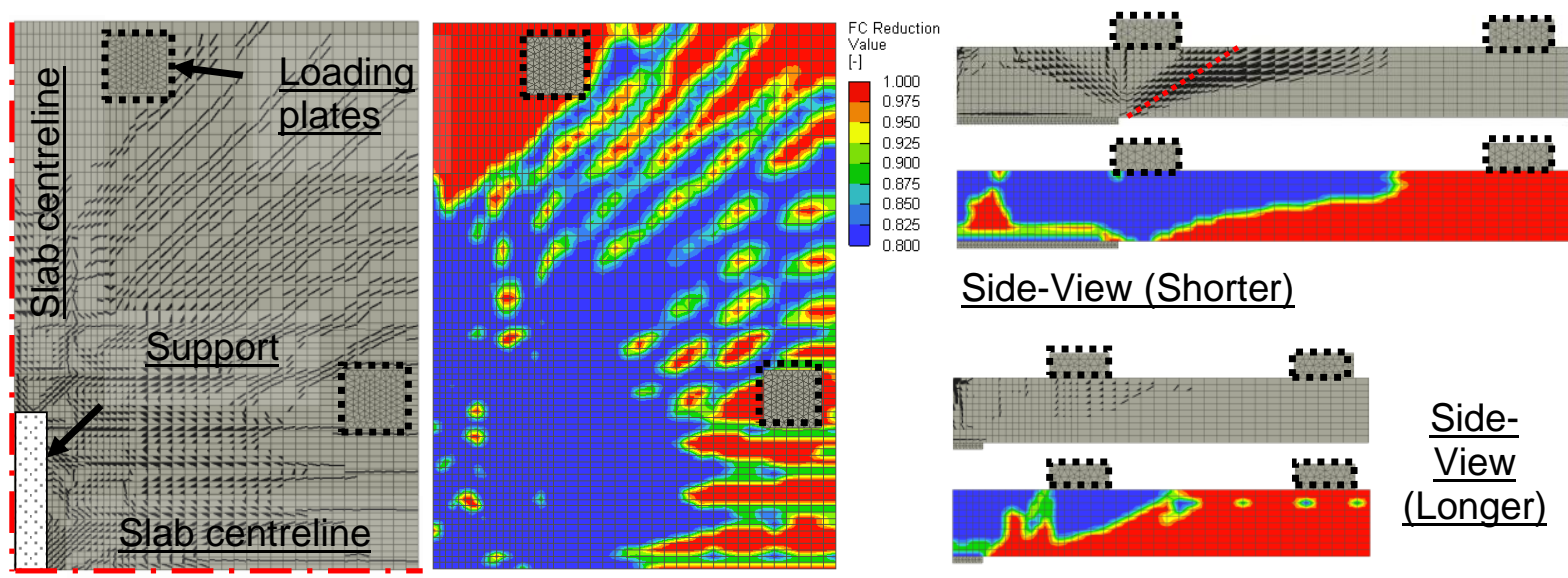

Side-View (Shorter)

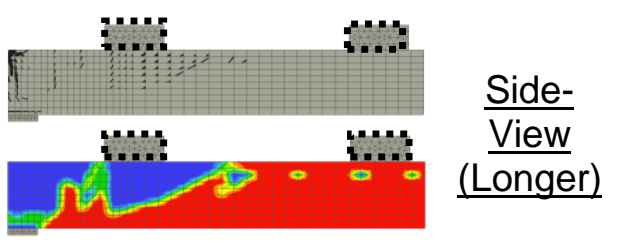

$\underline{\text { Top-View }}$
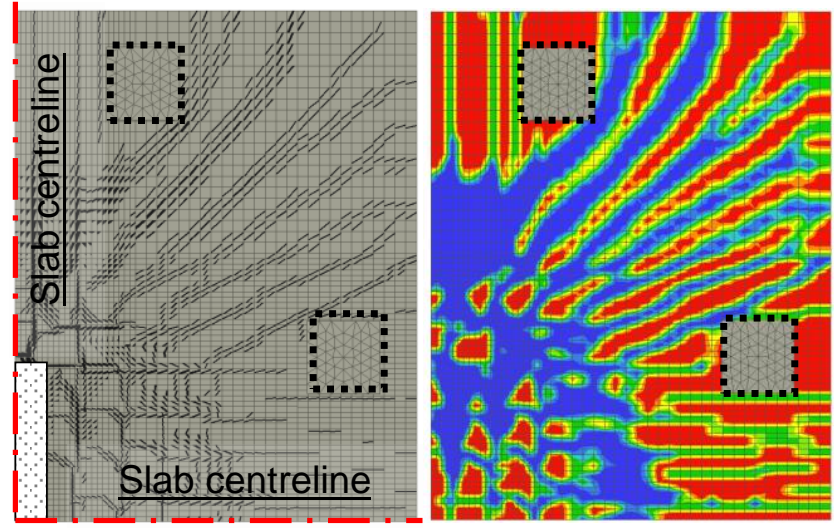

(a)

Top-View

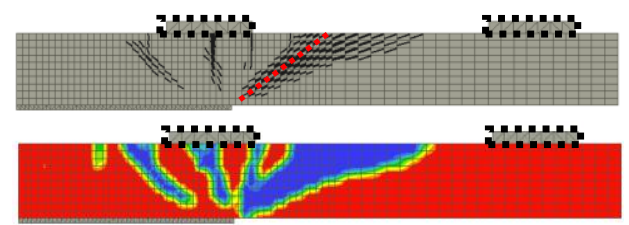

Side-View (Shorter)

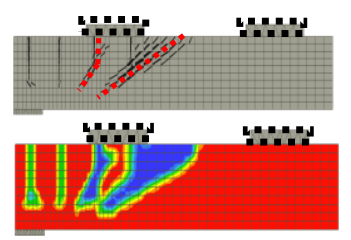

Side-

(Longer)

(b)

Figure 10. Plot of crack patterns and reduction of concrete compressive strength $\left(f_{c}\right)$ from top and side view (slab centreline) at predicted failure load of slab: (a) L5c; (b) OC15. 

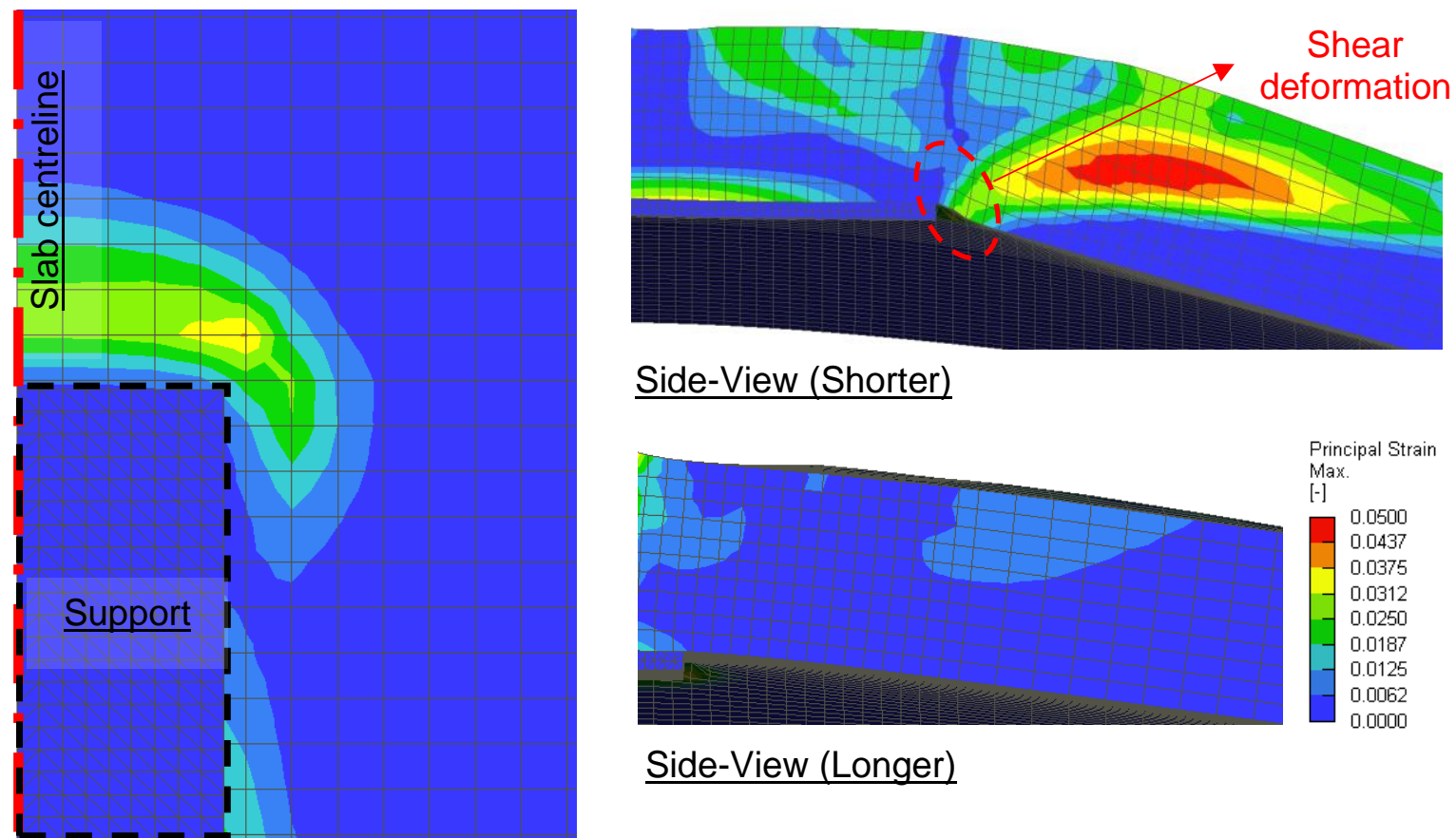

\section{Side-View (Shorter)}

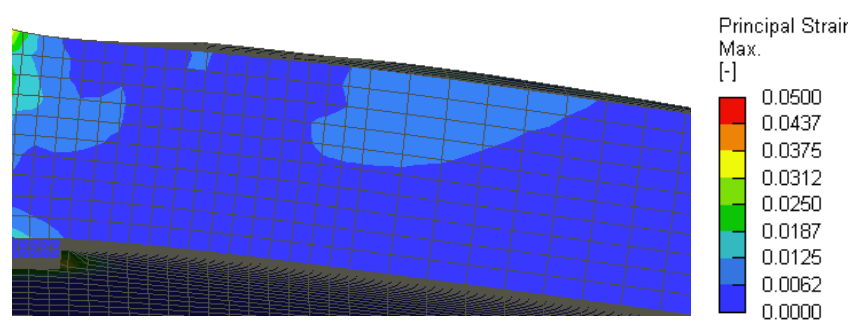

Side-View (Longer)

\section{Bottom-View (enlarged view from Figure 10(a))}

Figure 11. Plot of principal tensile strain and deformed shape (magnified 10x) of slab L5c at predicted failure load.

Shear force distribution around control perimeter: Shear field analysis [2, 5, 25] is a powerful technique for determining the shear resisting perimeter. In this approach, punching failure is related to the elastic shear force per unit length around the punching control perimeter. MC2010 [5] bases shear failure on the peak elastic shear force per unit length. This approach is illustrated in Fig. 12 which shows the elastic shear field and corresponding shear force distribution at $0.5 d$ from the column face for specimens OC13 and OC15 of Teng et al. [10] at the measured failure load. Basing shear failure of the peak elastic shear force per unit length is conservative as illustrated in Fig. 13 which shows shear force per unit length around a control perimeter located at $0.5 d$ from the column face (see Fig. 14 in which the reduced control perimeter of MC2010 is shown in bold). Fig. 13 shows the resulting shear forces in L3c, L5c, OC13 and OC15 at four different load levels relative to the predicted failure load $P_{u}$. Also included in Fig. 13(c) and Fig. 13(d) are the elastic shear force distributions from Fig. 12. Three conclusions are drawn from Fig. 13. First, shear forces per unit length are significantly greatest around the corner region of the control perimeter and least along the parts of the control perimeter neglected by MC2010. This suggests that failure of slabs supported on elongated columns is triggered locally around the corner region prior to full mobilisation of resistance elsewhere. Second, the shear force that is resisted by the parts of the perimeter neglected by MC2010 becomes progressively more significant as the support length increases. Third, increasing load from $0.9 P_{u}$ to $P_{u}$ caused the shear force to decrease within the diagonal (corner) region but increase disproportionately along the long side. This behaviour results from shear redistribution of the type identified by Sagaseta et al. [16] which reduces the peak shear force 
below that calculated with elastic analysis as illustrated in Fig. 13(c) and Fig. 13(d) making the shear field approach of MC2010 conservative [25]. Fig. 13(b) and (c) also show the variation in shear force per unit length beyond the strain-based estimate of failure load. The post failure shear forces are shown at the loads indicated with square green markers in Fig. 9(c) and (d). Fig. 13(b) and (c) show that the increase in load between the failure point and green marker in Fig. 9(c) and 9(d) is accompanied by i) a significant increase in shear force along the longer side and discounted region of the control perimeter and ii) a drop in shear force elsewhere. Such an extent of redistribution overestimates resistance and is unrealistic since, in reality, failure occurs prior to the redistribution owing to sudden loss of resistance around the corner regions. Adoption of the proposed strain-based failure criterion (Section 2.2) provides a realistic limit on the degree of shear redistribution which is otherwise overestimated within ATENA.

Variation of Tangential to Radial strain ratio $(T / R)$ in slab soffit: Fig. 15 shows the variation in strain ratio T/R around the MC2010 control perimeter of slabs L3c, L5c, OC13 and OC15 at the load stages depicted in Fig. 13. The results in Fig. 15 are pertinent to design codes which position the punching control perimeter at $0.5 d$ from the column face. Consequently, such codes need to adopt different shear resistances for punching and linear shear. This is not the case for EC2 which positions the punching control perimeter at $2 d$ from the column face thereby allowing the the same shear resistance to be used for linear and punching shear. The ratio T/R is reasonably independent of load until near failure when it increases significantly around the corner and short sides of the control perimeter, where shear stress is greatest, due to the radial strain dropping to near zero. The difference in T/R between the discounted region and the remainder of the control perimeter becomes pronounced at all load stages as $c_{\max } / d$ increases above around 5 to 6 dependent on slab geometry and loading arrangement. The NLFEA results suggest that coexistent tangential strain increases the shear resistance from linear (one-way) to punching around the effective MC2010 control perimeter (see Fig. 4(a)).

This description of behaviour is consistent with the experimental findings of Filatov [26] who investigated the influence of support shape and size on radial and tangential strain in the soffit of concentrically loaded internal slab-column punching specimens. Filatov [26] tested four specimens with slab thickness of $140 \mathrm{~mm}$ having the following support shapes: 1) circular with diameter of $210 \mathrm{~mm}, 2$ ) $200 \mathrm{~mm}$ square, 3) $200 \times 500 \mathrm{~mm}$ and 4) $200 \times 800 \mathrm{~mm}$. Strains were measured near the support by means of strain gauges placed in radial and tangential directions. Close to failure, tangential strains were relatively uniform around the circular column but greatest around the corners of the square and rectangular supports. In specimens with a rectangular support, the tangential strains along the longer column side reduced with distance from the column corner and were a minimum at the slab centreline. In the test with the $200 \times 800 \mathrm{~mm}$ support, the tangential strain at the slab centreline was only about $3.0 \%$ of the peak tangential strain at the corner. Additionally, the variation in radial strain was small compared with the variation in tangential strain [26]. 

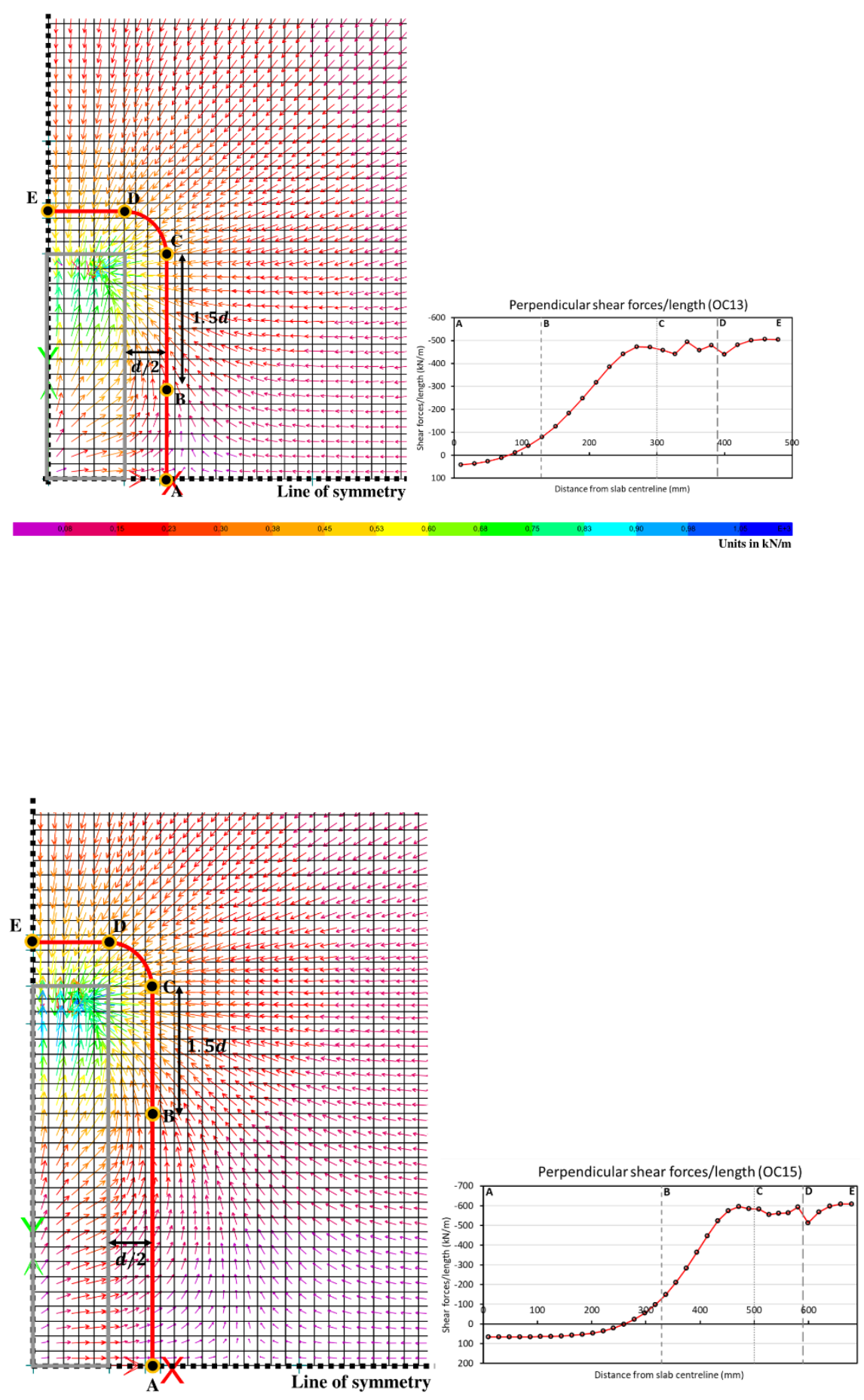

Units in $\mathbf{k N} / \mathbf{m}$

Figure 12. Elastic shear fields for slabs OC13 (top) and OC15 (bottom) of Teng et al. [10] at measured failure load. 

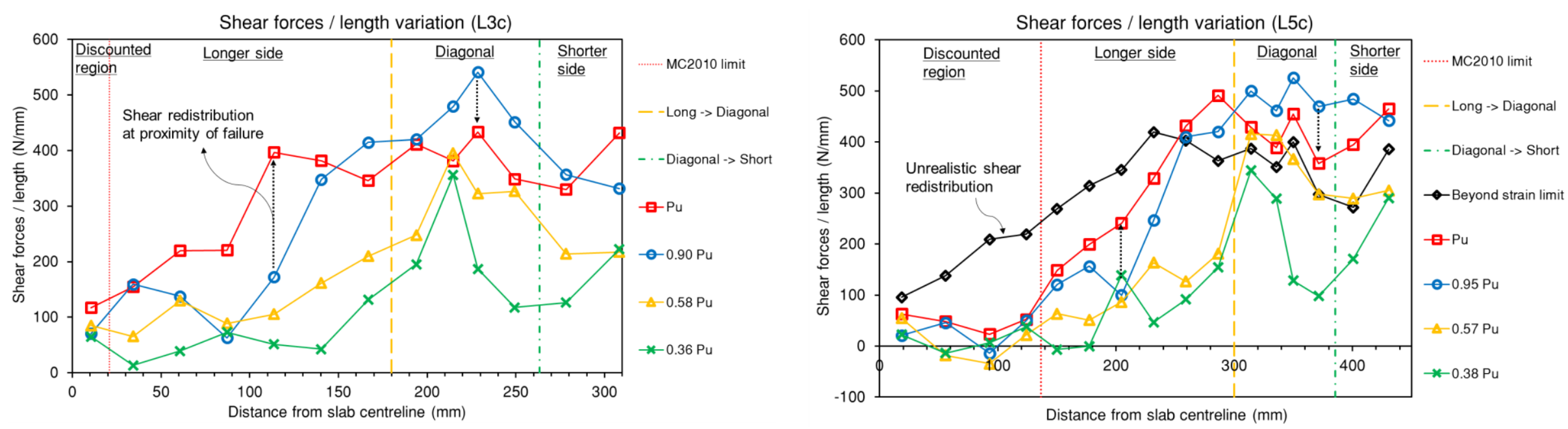

(a)
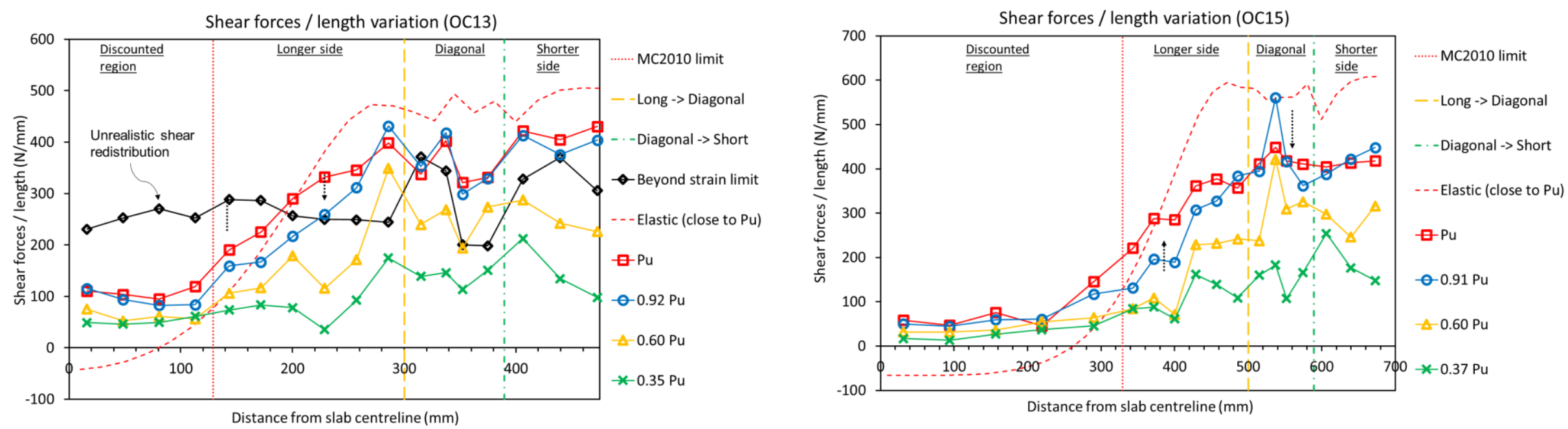

(c)

(d)

Figure 13. Variation of shear force/length along the quarter of the control perimeter of slabs: (a) L3c; (b) L5c ; (c) OC13; (d) OC15. 

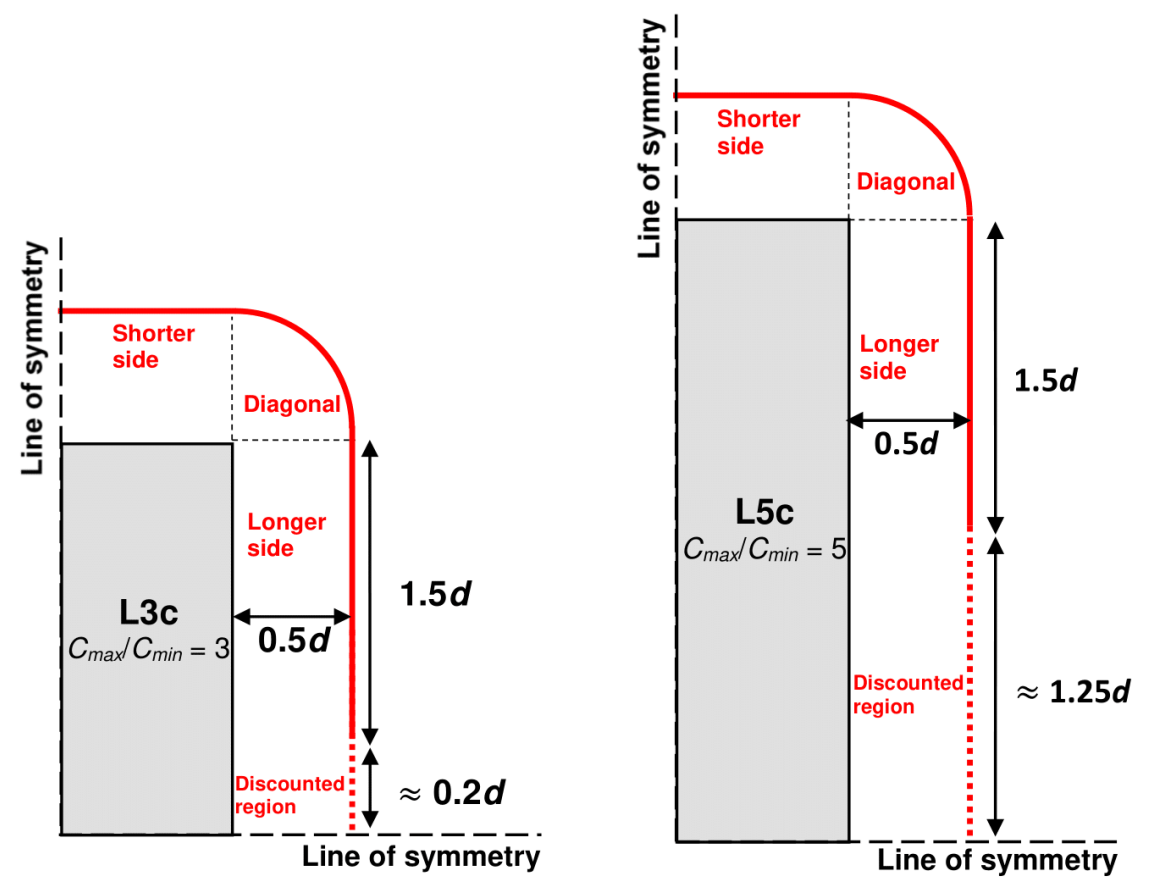

Figure 14. Regions of control perimeter for extraction of shear forces per unit length for slabs: (a) L3c; (b) L5c. 


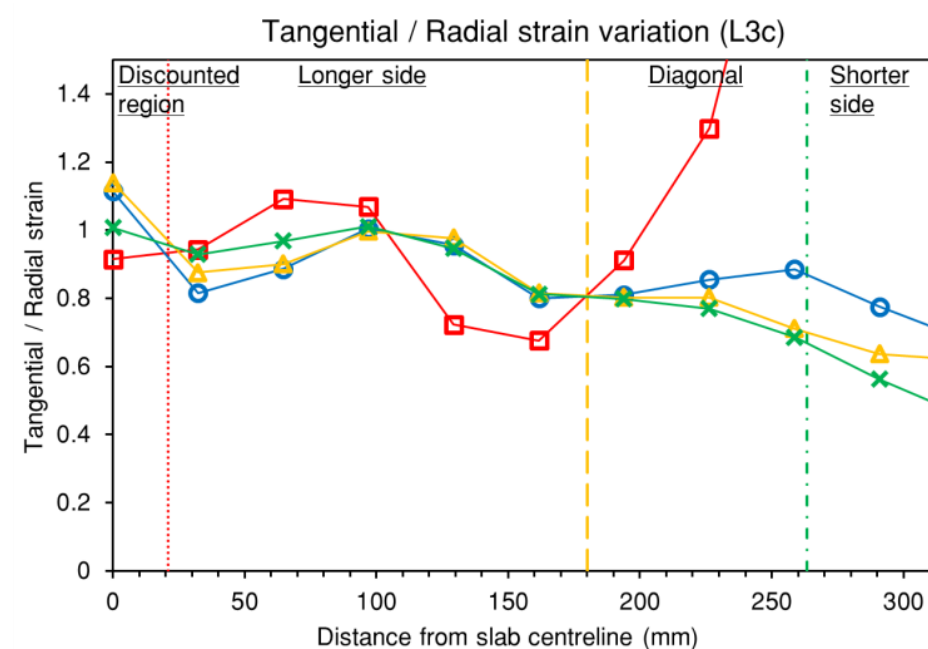

(a)

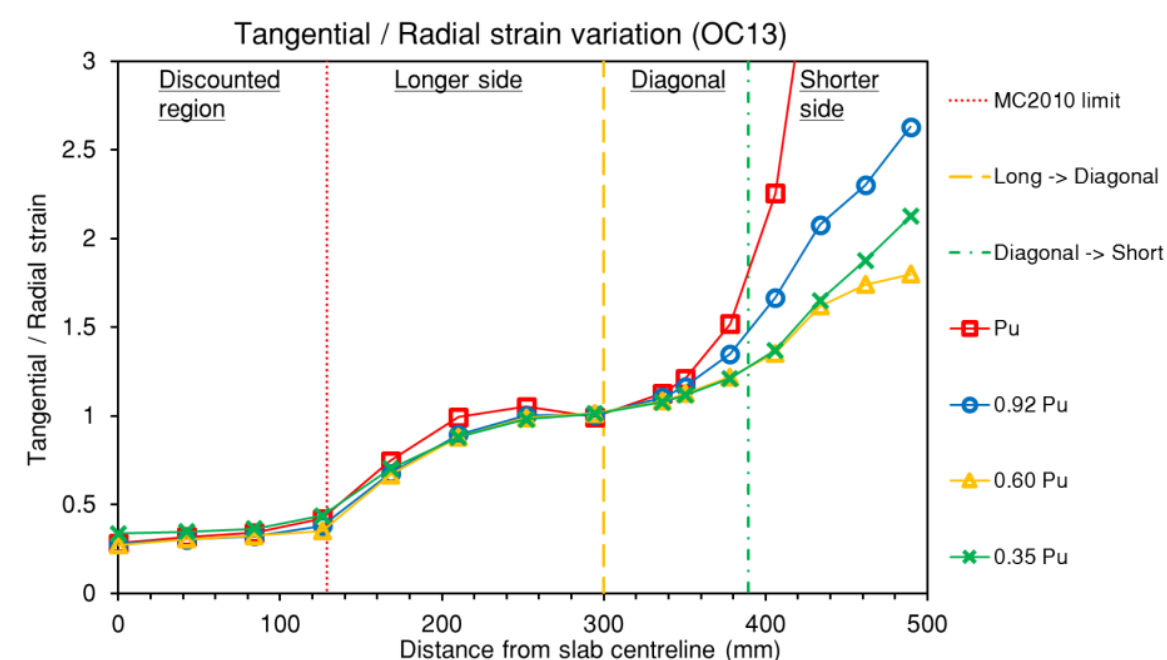

(c)

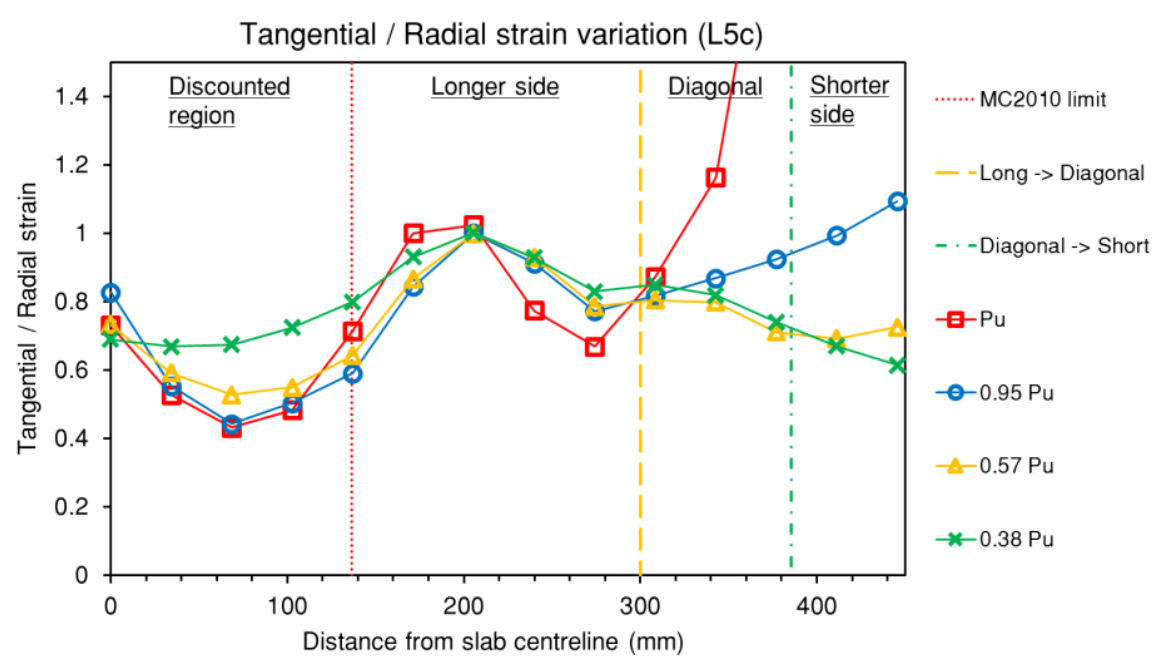

(b)

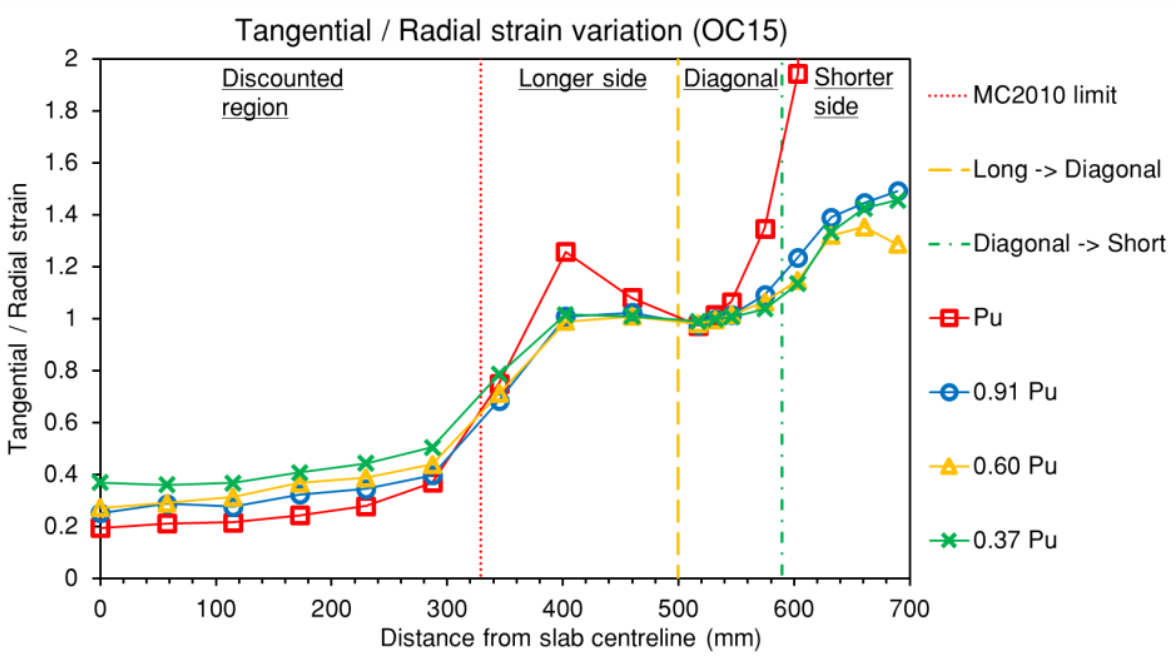

(d)

Figure 15. Variation of tangential / radial strain (T/R) along the quarter of the control perimeter of slabs: (a) L3c; (b) L5c; (c) OC13; (d) OC15. 
Support (spring) reaction: Fig. 16 presents contours of the support reactions for slabs L5c, OC13 and OC15 at the predicted failure load $\left(P_{u}\right)$. In these analyses, the supports of the slabs of Teng et al. [10] were modelled as steel plates (with no-tension springs) to allow the effective support length to be extracted whereas in reality stub columns were provided. Section 2.4, and Fig. 9(e), show that introducing no-tension springs under the support has little influence on the predicted failure load compared with utilising a clamped support to simulate a stub column. The blue contours in Fig. 16 depict regions of uplift where the slab separated from the support. The effective compressive region is seen to be concentrated at the corners of the support with length varying between $0.85 d-1.80 d$. Examination of Fig. 16 shows the orientation of the triangles of the steel baseplate to be different for slab OC13 than slabs L5c and OC15. This difference was unintentional but is considered unlikely to have influenced the global response of the slab which was meshed with hexahedral elements

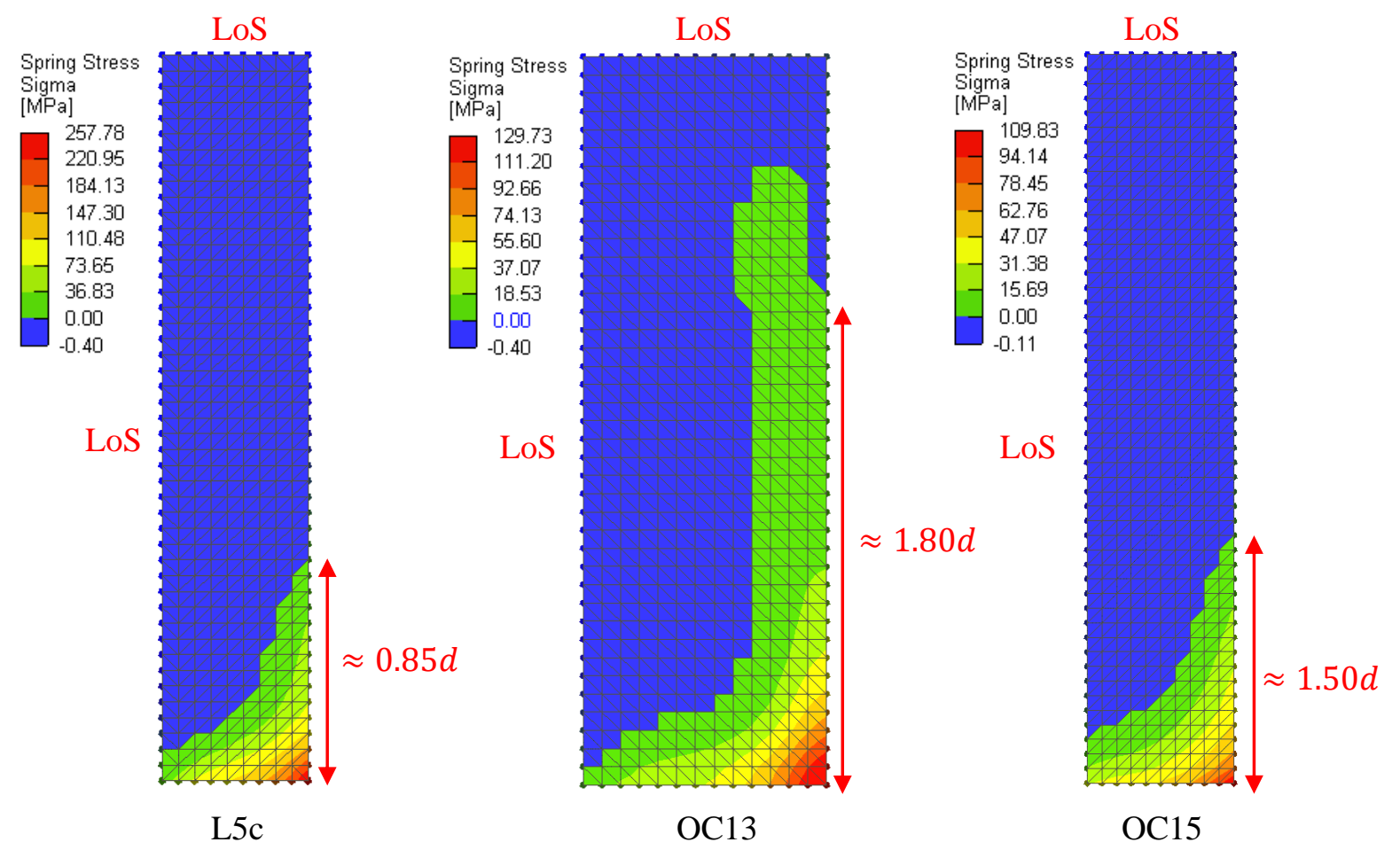

Figure 16. Contour of support reactions of slab: $\mathrm{L5c}, \mathrm{OC13}$, and $\mathrm{OC15}$ at predicted failure load (Notes: LoS denotes as lines of symmetry).

\subsection{Parametric studies}

\section{- Influence of $c_{\max } / \boldsymbol{d}$ to the proportion of one-way shear contribution}

A parametric study was carried out to determine the effect of increasing the support length beyond that tested by Oliveira et al. [1]. The slab geometry, material parameters, and reinforcement arrangement were kept the same as slab L5c but the longer column side was increased to $720 \mathrm{~mm}$ (L6c), $840 \mathrm{~mm}$ (L7c), $960 \mathrm{~mm}(\mathrm{~L} 8 \mathrm{c})$ and $1080 \mathrm{~mm}(\mathrm{~L} 9 \mathrm{c})$ giving column aspect ratios $\left(c_{\max } / c_{\min }\right)$ between 6 and 9 and $c_{\max } / d$ between 6 and 10. The aim of the study was to determine the influence of support length 
on the proportion of load carried by one- versus two-way shear around a control perimeter at $0.5 d$ from the support face. For consistency with the effective punching perimeter of MC2010, the border between one- and two-way shear regions was assumed to be located at $1.5 d$ from the corner of the support. The failure load was determined using the strain-based criterion described in Section 2.2. Fig. 17(a) and (b) show the load-rotation responses of slabs L3c - L9c along with the contribution of one-way shear as a function of $c_{\max } / d$. The one-way contribution is plotted at the predicted failure load $\left(P_{u}\right)$ for all slabs.

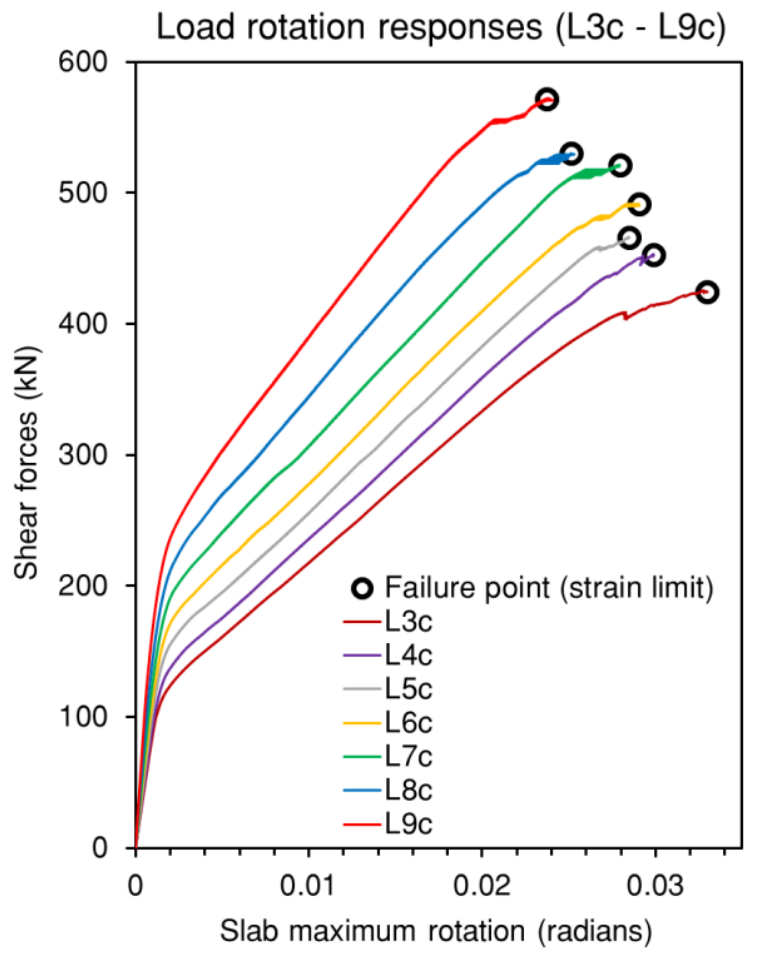

(a)

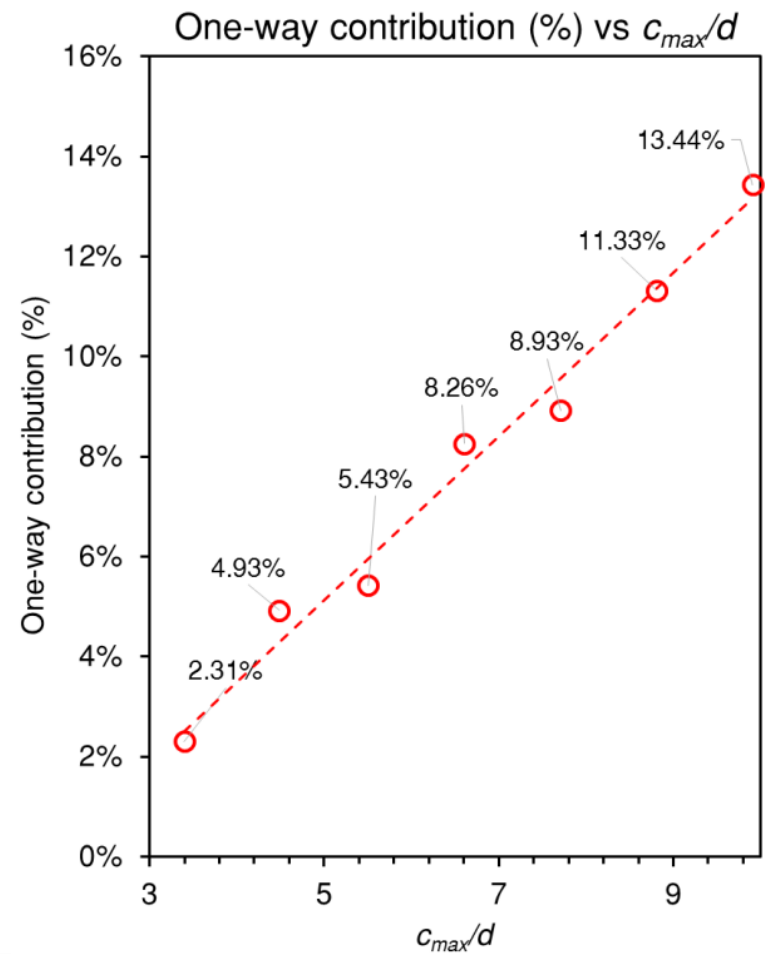

(b)

Figure 17. (a) Load-rotation responses; (b) \% of one-way shear contribution at predicted failure load $\left(\boldsymbol{P}_{\boldsymbol{u}}\right)$.

Fig. 17(a) shows that as the support length increases the predicted load-rotation response becomes stiffer and the failure load increases. Fig. 17(b) shows that the contribution of one-way shear increases linearly with support length. The reduced control perimeter of MC2010 is clearly applicable for $c_{\max } / d$ $\leq 6$ since the contribution of linear shear along the neglected parts of the perimeter is less than $5 \%$. For $c_{\max } / d>6$, the contribution of linear shear becomes progressively more significant reaching a maximum of $13.44 \%$ for slab L9c with $c_{\max } / d=9.9$. Hence, to produce more accurate and consistent estimates of shear resistance at large $c_{\max } / d$, the contribution of linear shear should be included.

\section{- Influence of clamping down the support (no uplift) vs simple support}

The slab was supported by a steel plate in the punching shear tests of Oliveira et al. [1]. Consequently, uplift was free to occur over the central part of the support plate unlike in flat slab buildings. The influence of uplift was investigated by reanalysing slabs L3c, L5c, L7c and L9c with top and bottom support plates clamped to the slab. Fig. 18 compares the resulting load-rotation responses and failure 
loads with those obtained previously using "non-tension spring" supports. Clamping is seen to not significantly influence either the rotation or failure load. Similarly, Fig. 9(e) shows that the strength of OC15, which had a stub column, was not significantly affected by modelling the support as a steel plate. Additionally, Fig. 19 shows that the variation in shear force/length is very similar for clamped and simply supported slabs apart from the slabs with clamped supports having slightly higher shear forces/length around the longer side of the control perimeter. Consequently, these analyses suggest that it is reasonable to simulate elongated column cross-sections with plates in laboratory tests.

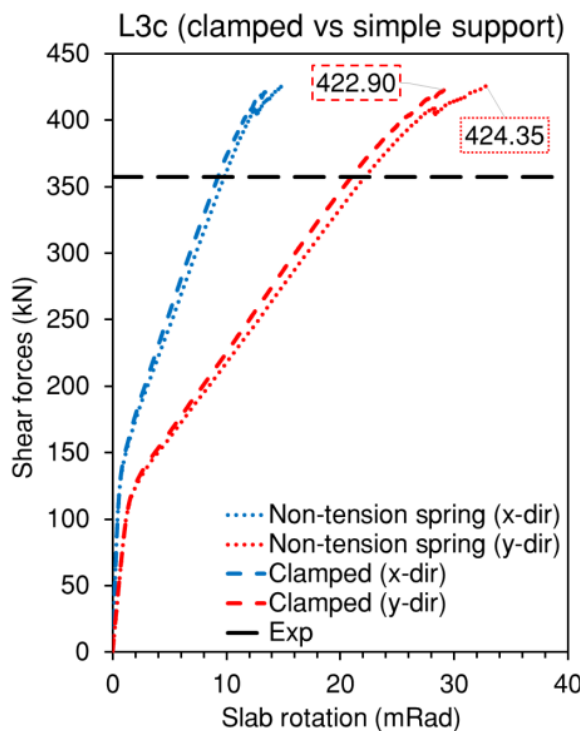

(a)

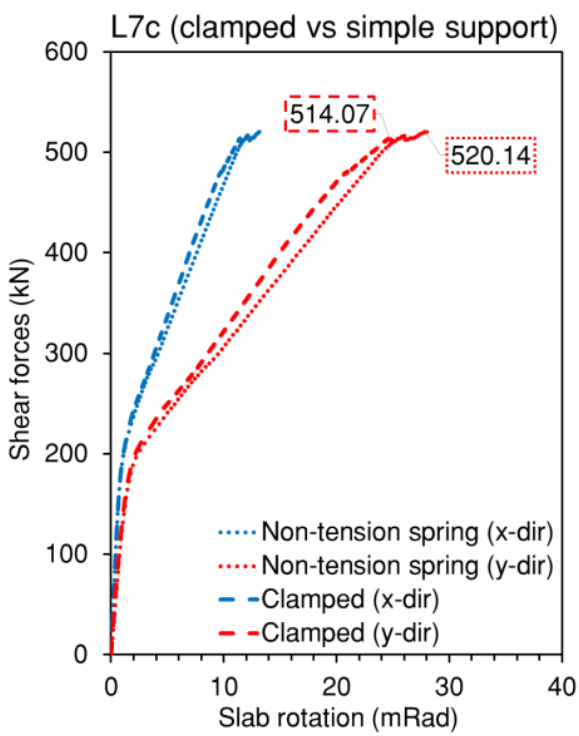

(c)

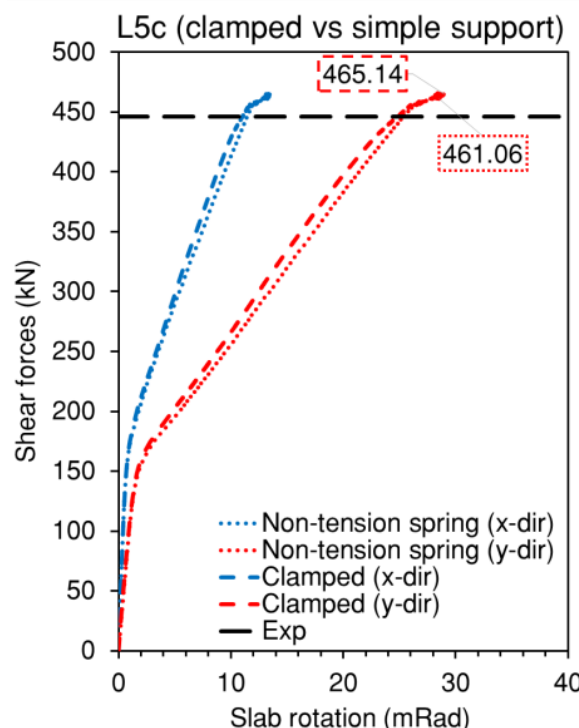

(b)

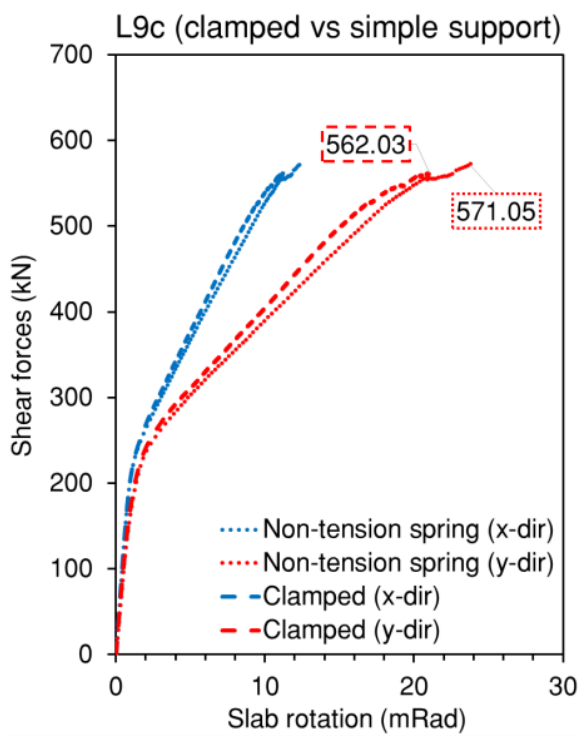

(d)

Figure 18. Influence of clamping down the column to slab load-rotation response and failure load for slabs: (a) L3c; (b) L5c; (c) L7c; (d) L9c. 

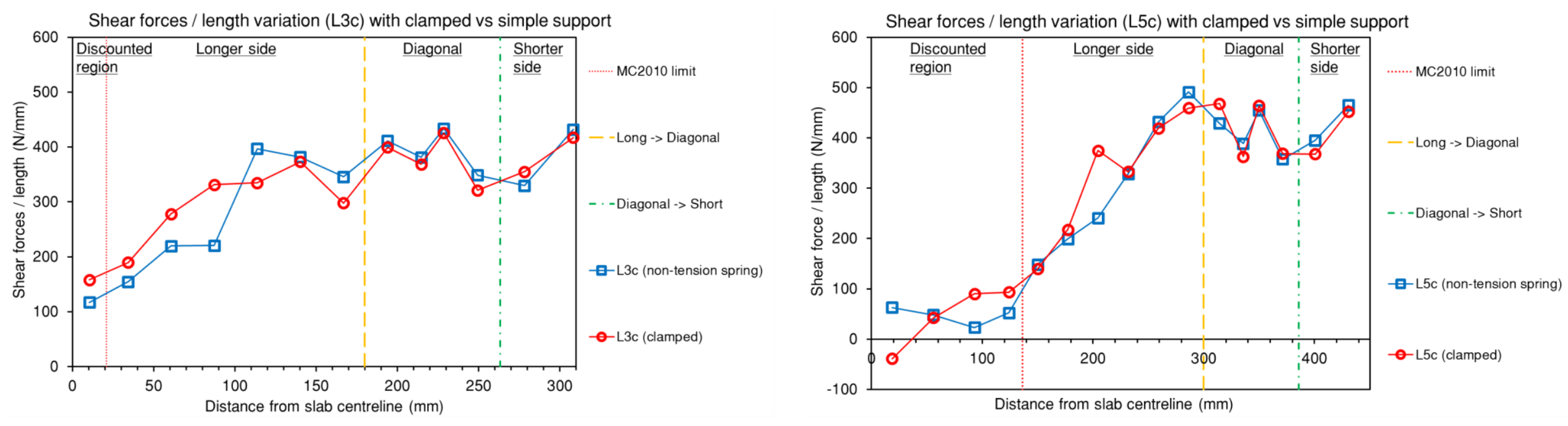

(a)

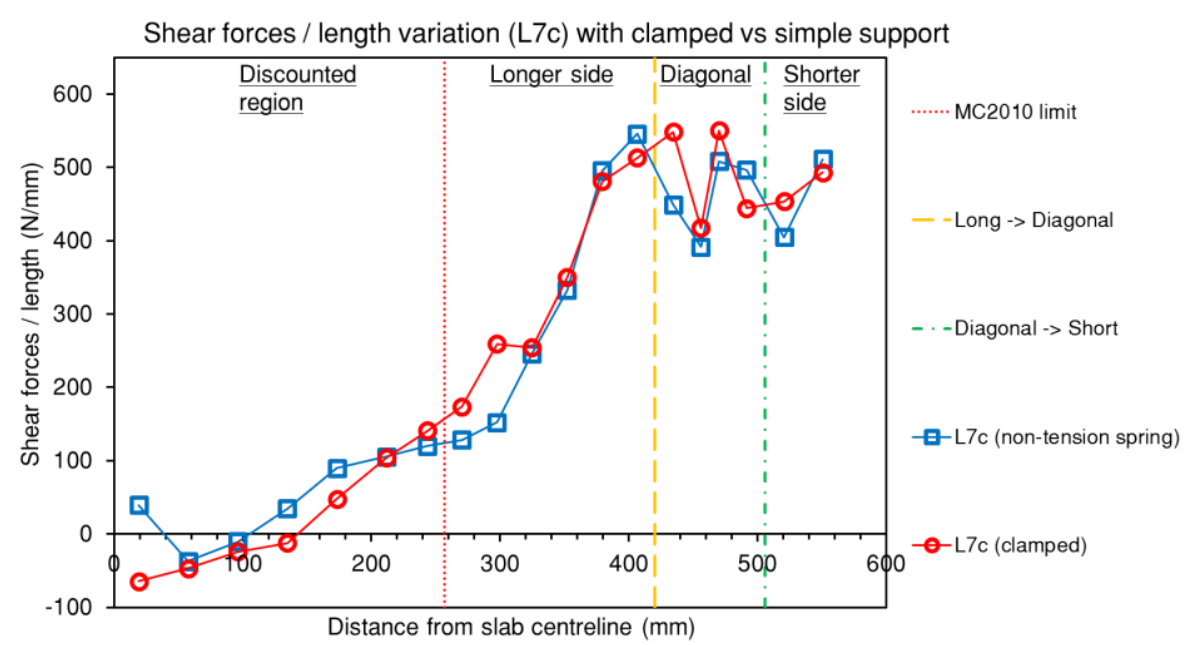

(c)

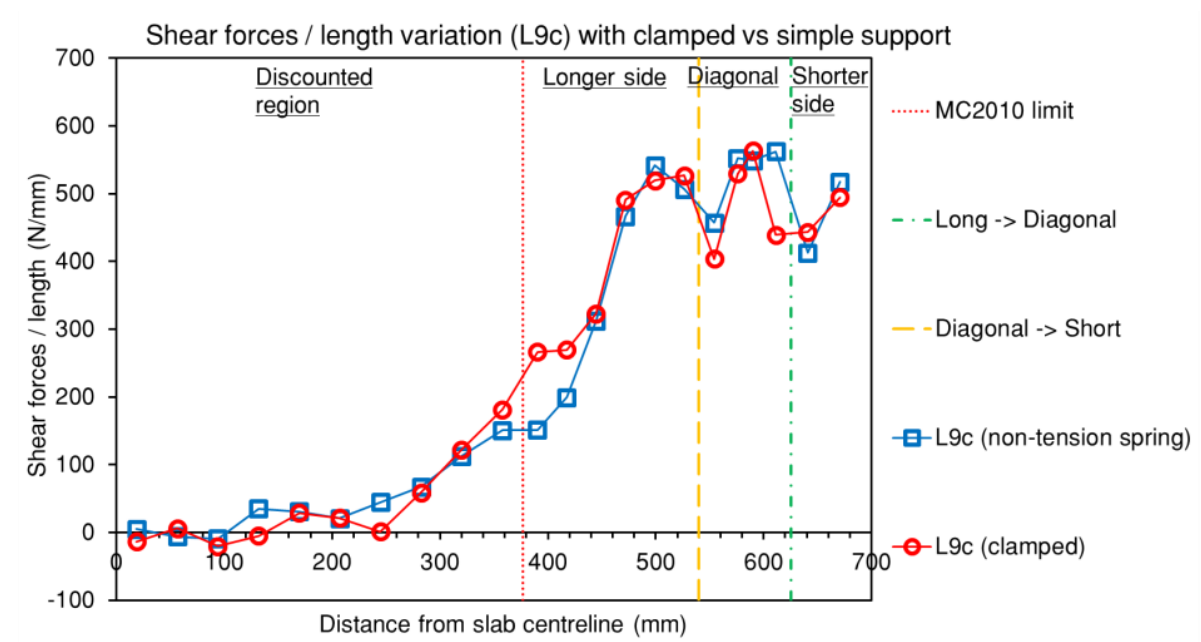

(d)

Figure 19. Influence of clamping down the column to shear force/length variation at predicted failure load $\left(P_{u}\right)$ for slabs: $(a)$ L3c; $(b)$ L5c; $(c)$ L7c; (d) L9c. 


\section{Combined joint and shell element model}

\subsection{Overview}

Despite giving valuable insights into punching failure, NLFEA with 3-D solid elements is too computationally demanding for the practical assessment of punching failure in building structures. To address this, the authors have previously proposed [6] a simplified approach in which the slab is modelled with 2-D nonlinear layered-shell elements and punching failure is simulated using discrete joint elements positioned around a control perimeter located at $0.5 d$ from the column face (where $d$ is the slab effective depth) (see Fig. 20(a)). In this paper the joint model is depicted JSPM (Joint Shell Punching Model). For evenly spaced joints, the strength of each joint $V_{c a p_{-} i}$ is related to its sector rotation $\psi_{s i}$ using the CSCT [7] as follows:

$$
V_{\text {cap } \_i}=\frac{V_{R}}{n}=\frac{0.75 b_{0,3 d} \cdot d \cdot \sqrt{f_{c}{ }^{\prime}}}{n\left(1+15 \frac{\psi_{s i} \cdot d}{d_{g 0}+d_{g}}\right)}(N)(3)
$$

where $V_{R}$ is the punching load capacity, $b_{0,3 d}$ is the length of effective control perimeter at $0.5 d$ from the column face according to MC2010 (see Fig. 4(a)), $d$ is the average effective depth of the slab, $f_{c}^{\prime}$ is the specified concrete compressive strength, $\psi_{s i}$ is the relative slab-column sector rotation, $d_{g}$ is the maximum aggregate size, $d_{g 0}$ is a reference aggregate size of $16 \mathrm{~mm}$ and $n$ is the number of joints. Slab rotations are monitored around the line of contraflexure for radial elastic moment where parametric studies show rotations to be close to a maximum and radial curvature minimal [27].

The constitutive behaviour of the joint element in the out-of-plane direction is represented by three main branches as follows:

- Stage I: linear elastic

- Stage II: each individual joint softens following the shape of the CSCT resistance curve

- Stage III: global connection failure following failure of all joint elements

Transition from Stage I to Stage II occurs at individual joints when the joint shear force first reaches the joint shear resistance. Transition from Stage II to Stage III in Fig. 20(b) depicts global failure which is assumed to occur at a relative vertical joint deformation of $1 \mathrm{~mm}$. Based on calibration studies [6], the limit of $1 \mathrm{~mm}$ is chosen to be: 1) sufficiently large that all two-way joints fail prior to the first joint entering the post-punching regime but 2) sufficiently low that the vertical displacement of the slab is realistic at the start of the post-punching regime. The exact choice of $1 \mathrm{~mm}$ is somewhat arbitrary but has no influence on the Stage III residual post-peak punching capacity of isolated slab column specimens. The joint resistance reduces linearly with joint displacement in Stage III until it reaches the post-peak punching resistance which is calculated using the mechanical model of Fernandez Ruiz et 
al. [28]. Fig. 20(a) illustrates the implementation of the proposed modelling strategy and Fig. 20(b) shows the constitutive behaviour of the joint element in the out-of-plane direction. Initially, the joint element is assumed to behave linearly with out of plane displacement stiffness $\left(k_{\text {inc }}\right)$ formulated as:

$$
k_{\text {inc }}=k_{\text {red }} \cdot \frac{E_{c}}{2(1+v)} \cdot l_{s} \quad(N / m m)(4)
$$

where $v$ is Poisson's ratio for concrete which is taken as $0.2, E_{c}$ is concrete elastic modulus, $k_{\text {red }}$ is a joint stiffness reduction factor and $l_{s}$ is the spacing between adjacent joint elements. Calibration studies [6] show that a suitable value for the joint stiffness reduction factor $k_{\text {red }}$ is 0.1 .

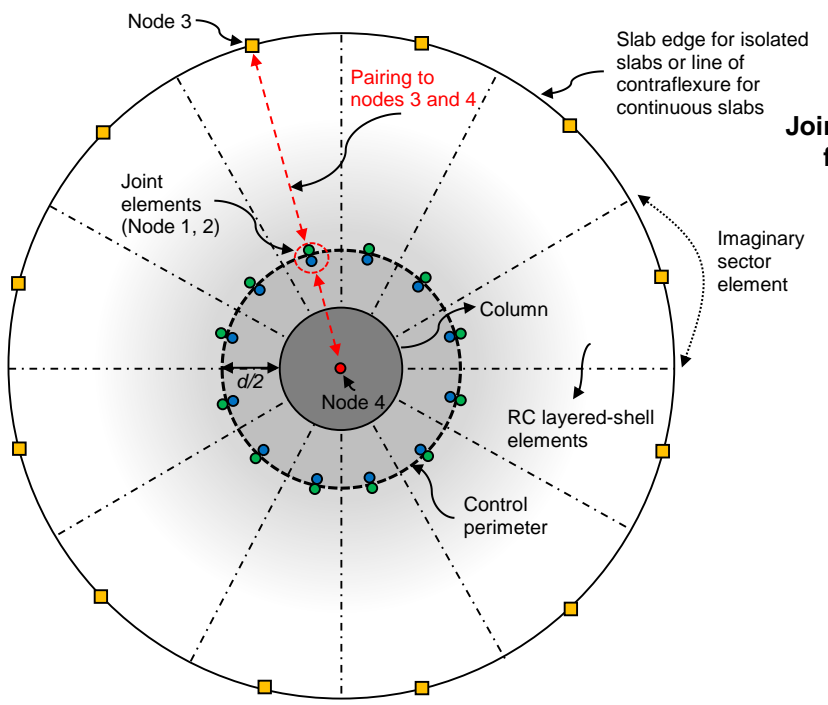

Plan View

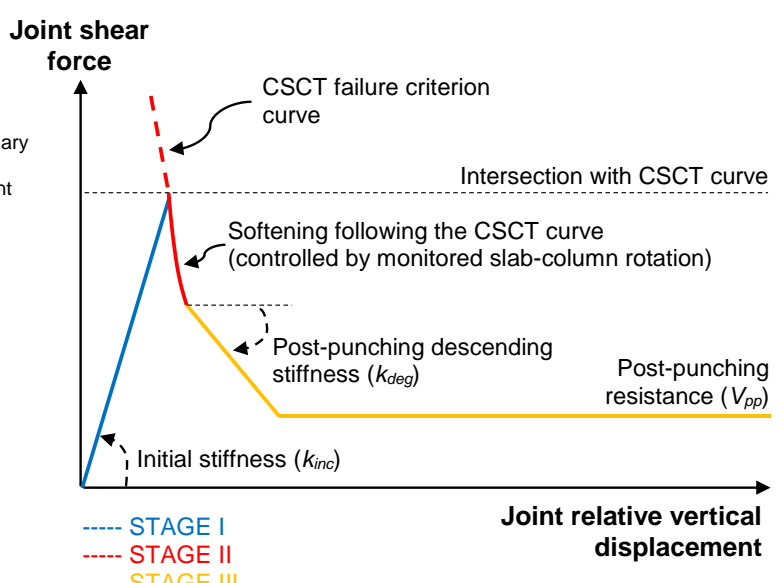

(b)

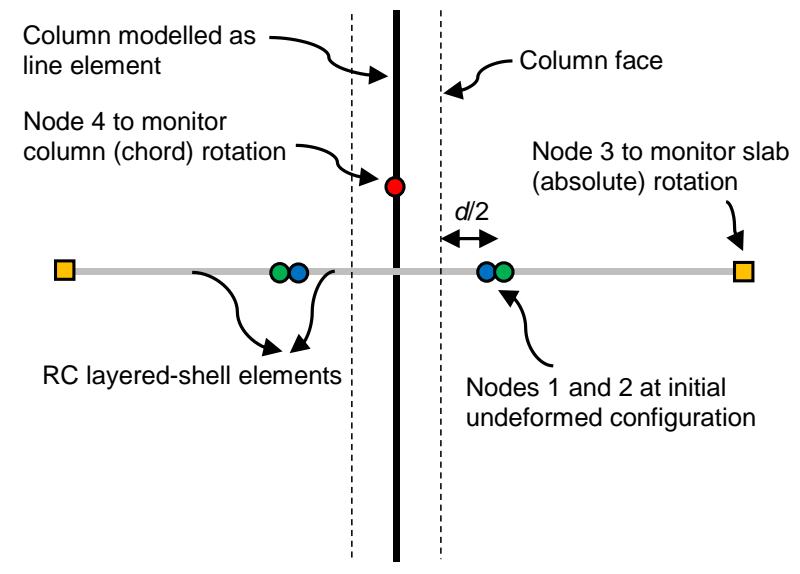

Elevation View

(a)

Figure 20. (a) Illustration of JSPM in plan and elevation; (b) Joint constitutive relationship for the out-of-plane DOF. 


\subsection{Implementation of JSPM into ADAPTIC [29]}

The JSPM is implemented in the nonlinear structural analysis program ADAPTIC [29] as described in [6]. The slab is modelled with nonlinear shell elements utilising the conventional Reissner-Mindlin hypothesis. The adopted shell element [30] is discretised into several in-plane layers through the slab thickness. Forces and moments are acquired from integration (Gauss integration scheme) of normal and shear stresses at $2 \times 2$ integration points in each layer. In this study, the slab was discretised into 10 layers through the slab thickness since previous calibration studies [6] showed this to capture the slab deformation accurately. Both geometric and material nonlinearities are considered within the shell element formulation. Concrete compressive behaviour is modelled using a plasticity approach in which compressive stress is determined from an evolving plastic interaction surface in the biaxial plane. Concrete tensile behaviour is formulated independently using a smeared fixed-crack approach in which the crack direction is determined from the principal stress direction at the moment of crack initiation. After cracking, in plane shear stiffness is reduced by a constant shear retention factor $\left(\beta_{s}\right)$. In this study, $\beta_{s}=0.1$ was adopted throughout. The choice of shear retention factor for the nonlinear shell elements has no significant effect on the predicted load rotation response, and hence the JSPM failure load, as previously shown by Soares [31]. Out-of-plane shear behaviour is assumed to be elastic as commonly assumed. Reinforcement is modelled with equivalent uniaxial plates of uniform thickness assuming perfect bond and a bilinear stress-strain curve (with minimal strain hardening). In this study, the concrete elastic modulus $\left(E_{c}\right)$ and concrete tensile strength $\left(f_{t}\right)$ were determined with Model Code 2010 [5] for consistency with the input parameters used in ATENA (see Table 2). As suggested by Vollum and Tay [32], the concrete tensile strength was reduced by a factor of two in ADAPTIC and the tensile softening slope was chosen to reduce tensile stress to zero at a strain of 0.001. Studies by Soares and Vollum [27], as well as the authors [6] show that this combination of parameters gives good estimates of experimentally obtained slab deformations up to and including flexural yield for flexural reinforcement ratios of $0.33 \%$ and above. This is sufficient for the present purpose where the shear resistance of the joint elements is assumed to depend on the relative slab-column rotation. Alternative modelling strategies, which include bond slip, may be required for more lightly reinforced slabs. Further details of the shell element formulation and concrete material modelling is given by Izzuddin et al. [30].

The 6-degree of freedom 3-D joint element depicted jel3 [29, 33] is used to simulate punching failure in the JSPM. The joint element incorporates independent nonlinear force-deformation relationships for each DOF (uncoupled behaviour). Each joint element consists of two coincident nodes $\left(1^{\text {st }}\right.$ and $2^{\text {nd }}$ node). The relative out-of-plane deformation between these two nodes represents the separation of the punching cone from the surrounding slab at failure. The joint element algorithm allows the slab rotation to be monitored at user-defined positions throughout the analysis. This allows the joint resistance to be continually updated during the analysis and enables the CSCT to be implemented without post 
processing. The algorithm requires two additional nodes to be paired with each joint element to provide the slab rotation $\left(3^{\text {rd }}\right.$ node) and the column chord rotation $\left(4^{\text {th }}\right.$ node) respectively. The difference between the two gives the relative slab-column rotation which is used in the CSCT to calculate the joint shear resistance with Eq. 3. The $3^{\text {rd }}$ and $4^{\text {th }}$ nodes are also required to define the initial local axes of the joint element. The local $\mathrm{x}$-axis is initially defined by a vector connecting nodes 1 and 3 while the local $\mathrm{y}$-axis lies in a plane defined by the local $\mathrm{x}$-axis and node 4. All joint DOFs, except out-of-plane deformation are modelled as fully rigid.

\subsection{Previous validation and further refinements for elongated column scenario}

The proposed JSPM modelling strategy has been validated [6] for 47 isolated internal slab-column connections with mostly square columns. The validation considers the variation of a) flexural reinforcement ratio $(0.33 \%$; $0.80 \%$; and $1.50 \%)$, b) slab thickness (125 mm (half-size); $250 \mathrm{~mm}$ (fullsize); and $500 \mathrm{~mm}$ thickness (double-size)) (size effect), c) amount of integrity reinforcement (only flexural reinforcement, 4-D8 integrity bars, 4-D10 integrity bars) (post-punching capacity), d) in-plane compressive forces (edge compressive stress of 1.25 MPa, 2.50 MPa and 5.0 MPa) and e) loading eccentricity (a) constant loading eccentricity of either $130 \mathrm{~mm}$ or $577 \mathrm{~mm}$; b) increasing eccentricity with constant gravity shear ratio of $0.4,0.5$ and 0.8 ). The average measured/predicted failure load was 1.00 with a $\mathrm{CoV}$ of 0.097 . This paper refines the model and extends its application to slabs having elongated supports. The refined model is validated using a database from the literature consisting of 24 slabs (see Table 3) with elongated supports.

\section{- Treatment of one- vs two-way joint types}

The NLFEA with 3-D solid elements shows that the parts of the control perimeter included in MC2010 (i.e. $b_{0,3 d}$ ) resist load through punching shear while the omitted parts resist shear through one-way action. This suggests that one-way (linear) and two-way (punching) joints elements are required to realistically model punching shear failure at elongated supports. However, it is reiterated that punching failure is triggered locally around the corner of the support before full mobilisation of one-way shear resistance. In the model, one-way joint elements are allocated a nominal one-way shear resistance calculated at flexural yield (lower-bound) using the CSCT based failure criterion of Cavagnis et al. [34]. The resulting one-way joint shear resistance, which is independent of rotation, is given by:

$$
V_{1 \_ \text {way }}=v_{c_{-} \text {min }} \cdot l_{s}=\frac{k \cdot d \cdot \sqrt{f_{c}^{\prime}}}{\sqrt{\varepsilon_{y} \cdot \frac{d}{d_{d g}}}} \cdot l_{s}(N)(5)
$$


where $v_{c_{-} \min }$ is the minimum shear resistance per unit length, $k=0.019, \varepsilon_{y}$ is the flexural reinforcement yield strain, $l_{s}$ is joint spacing, and $d_{d g}$, which represents crack roughness, is calculated as follows:

$d_{d g}=\min \left(40 \mathrm{~mm}, 16+d_{g}\right)$ for $f_{c}^{\prime} \leq 60 \mathrm{MPa}$

$d_{d g}=\min \left(40 \mathrm{~mm}, 16+d_{g}\left(\frac{60}{f_{c}^{\prime}}\right)^{2}\right)$ for $f_{c}^{\prime}>60 M P a$

Fig. 21(a) shows the locations of one- and two-way joint types adopted in the modelling of slab OC15 which was typical. Initially, one-way joints were positioned along the complete length of the segments of the punching control perimeter neglected by MC2010 but this overestimated shear resistance. Consequently, the model was refined as shown in Fig. 21(a) by leaving a gap of length of $1.5 d$ between the ends of the reduced MC2010 perimeter $\left(b_{0,3 d}\right)$ and the first one-way shear joint. This adjustment is consistent with the earlier observation that the contribution of one-way shear is minimal for $c_{\max } / d \leq$ 6 (see Fig. 17(b)). For slabs supported on elongated columns, the line of contraflexure is assumed to be elliptical in shape as shown in Fig. 21(b).

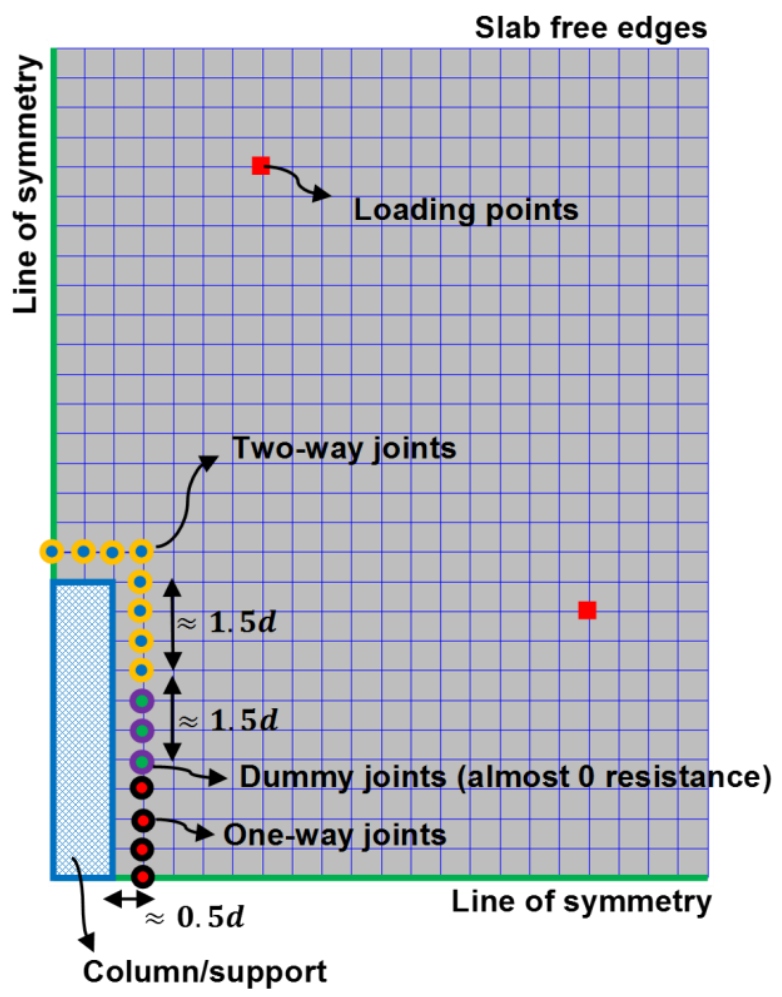

(a)

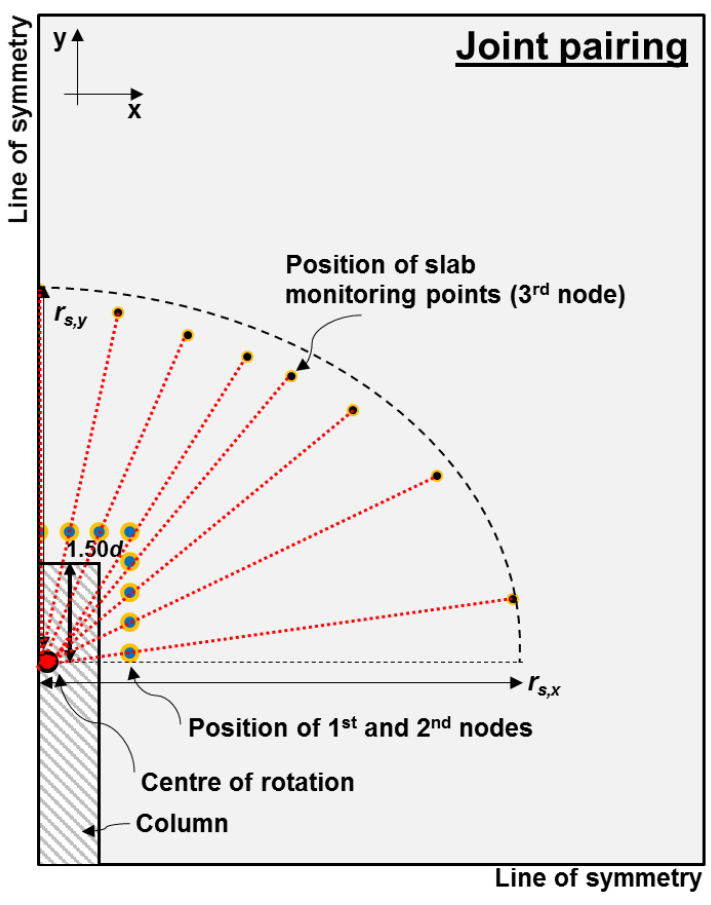

(b)

Figure 21. (a) JSPMR with dummy one-way joints within 1.5d gap; (b) Positioning of slab monitoring points $\left(3^{\text {rd }}\right.$ node) in JSPMR.

The refined joint shell punching model (see Fig. 21(a)) is depicted JSPMR. The joint resistance is calculated with Eq. 3 in terms of radial rotations calculated relative to the centre of rotation which is 
assumed to be positioned at $1.5 d$ from the end of the longer column side as shown in Fig. 21(b). Rotation is monitored at the $3^{\text {rd }}$ node of each joint which is positioned near the line of radial contraflexure which is assumed to vary elliptically in position between $r_{s, x}$ and $r_{s, y}$ as shown in Fig. 21(b).

\subsection{Validation of JSPMR with test data}

A database of 24 isolated internal punching shear tests (see Table 3) without shear reinforcement and $c_{\max } / d>3.0$ was used to validate the refined joint model. All the slabs failed in punching or combined flexure and punching. Loading types A to D were considered in which Type A depicts one-way bending parallel to the longer support dimension (Fig. 2(a) left), Type B depicts one-way bending parallel to the shorter support dimension (Fig. 2(a) right) and Type $\mathrm{C}$ depicts two-way bending with equal load in both $\mathrm{x}$ - and y-direction (Fig 2(b) left). Type D is similar to Type $\mathrm{C}$ but with unequal loads applied in $\mathrm{x}$ - and $\mathrm{y}$ - direction (Fig 2(b) right). Fig. 22 and Table 4 show the influence of $c_{\max } / d$ on the accuracy of failure loads calculated with ACI 318-14 [4], EC2 [3], the CSCT [7] with maximum rotation (LoA IV-CSCT $\left.\left(\psi_{\max }\right)\right)$, the CSCT with the simplified shear redistribution of Sagaseta et al. [16] (LoA $\left.\operatorname{IV-CSCT}\left(\psi_{x-y}\right)\right)$ and JSPMR. For all considered approaches, capacity reduction and partial factors were taken as 1.0. The markers in Fig. 22 depict the loading arrangement type which influences the accuracy of predictions. The virtual slabs L6c - L9c from the parametric studies are also included in Fig. 22 since experimental data are scarce for $c_{\max } / d>6$. Additionally, Fig. 22(e) includes JSPM predictions for the specimens with $c_{\max } / d \leq 3$ used in the previous validation of the model [6]. These additional data points are depicted axis-symmetrical (PS) and non-axis-symmetrical (PS) where asymmetry results from either loading or orthotropic flexural reinforcement [6]. The statistics shown in Fig. 22 and Table 4 only consider the 24 slabs in Table 3.

The CSCT predictions in Fig. 22 were made using Eq. 3 in conjunction with the reduced control perimeter of MC2010 $\left(b_{0,3 d}\right)$ [5]. In MC2010 LoA IV $\left(\psi_{\max }\right)$, the predicted failure load is given by the intersection of the load rotation based on maximum slab rotation and resistance curves. In this paper, the load-rotation response was determined with ADAPTIC using nonlinear shell elements. The LoA IV-CSCT $\left(\psi_{x-y}\right)$ method [16] discretises the control perimeter into four segments - two segments for each orthogonal direction. Consequently, the punching resistance of the slab is determined as the summation of the resistance contributed from each segment. The total shear resistance $\left(V_{R}\right)$ is formulated as:

$$
V_{R}=\frac{V_{R x}}{b_{0}} b_{x}+\frac{V_{R y}}{b_{0}} b_{y}(7)
$$


where $V_{R x}$ and $V_{R y}$ are the strengths calculated using Eq. 3 with $\psi_{x}$ and $\psi_{y}$ (slab rotation in x- and yaxis). The dimensions $b_{x}=2 c_{x}+0.5 \pi d$ and $b_{y}=2 c_{y}+0.5 \pi d$ are the lengths of the control perimeter perpendicular to the $\mathrm{x}$ and $\mathrm{y}$ axes, respectively. The dimensions $c_{x} \leq 3 d$ and $c_{y} \leq 3 d$ are the effective column cross section dimensions perpendicular to the $\mathrm{x}$ and $\mathrm{y}$ axes.

Fig. 22(a) shows that although safe ACI 318-14 gives the largest scatter of the methods considered with no clear trend between the predictions for two-way and one-way loading. Fig. 22(b) shows that EC2 gives good strength predictions for all the slabs with the caveat that its predictions are least safe for oneway loading as noted by [1]. Fig. 22(c) shows that CSCT $\left(\psi_{\max }\right)$ gives excellent predictions for $c_{\max } / d$ $\leq 6$ but is conservative for greater $c_{\max } / d$ due to neglect of the one-way shear contribution. CSCT $\left(\psi_{\max }\right)$ gives good predictions for both one and two-way loading arrangements since it accounts for the influence of loading type on rotation. Fig. 22(d) shows that CSCT $\left(\psi_{x-y}\right)$ gives excellent strength predictions for two-way loaded slabs but it tends to be unsafe for one-way loaded slabs. The improved predictions of CSCT $\left(\psi_{x-y}\right)$ for $c_{\max } / d>6$, compared with CSCT $\left(\psi_{\max }\right)$ arise from the increase in resistance due to shear redistribution. Fig. 22(e) shows that JSPMR produces very similar predictions to $\operatorname{CSCT}\left(\psi_{x-y}\right)$ despite the additional one-way joint contribution in the refined joint model. This reflects the complex interaction between one-way shear and shear redistribution around $b_{0,3 d}$.

\section{- Modification to JSPMR for one-way loading and at very elongated columns or walls}

The reduced safety of the one-way loading predictions in Fig. 22(d) and (e) appears to result from reduced shear redistribution for one-way compared with two-way loading but further research is required to confirm this. In the meantime, if using the JSPMR for one-way loading it is suggested that the joint shear resistance calculated with Eq. 3 is multiplied by $\alpha=0.85$. This procedure gives safe predictions of shear resistance for the slabs in Table 3 as shown in Fig. 22(f). Alternatively, CSCT $\left(\psi_{\max }\right)$ can be used.

As shown by the ATENA analysis, punching failure of slabs supported on elongated supports is triggered by localised shear failure around the end of the support prior to full mobilisation of shear resistance elsewhere. In the JSPM, global failure is accompanied by failure of all the joints. The adoption of this failure criterion in the JSPMR leads to it progressively overestimating punching resistance at the ends of elongated supports as $c_{\max } / d$ increases above 10 . This is due to excessive shear redistribution like that which occurred in the ATENA analyses unless limited by the adopted strain-based failure criterion. Shear redistribution can be limited in the JSPMR by relating failure to the vertical separation of the two-way joints which increases significantly subsequent to failure of all the joints around $b_{0,3 d}$. The introduction of such a displacement limit was not required for any of the slabs considered in Fig. 22 for which $\frac{c_{\max }}{d}<10$. 


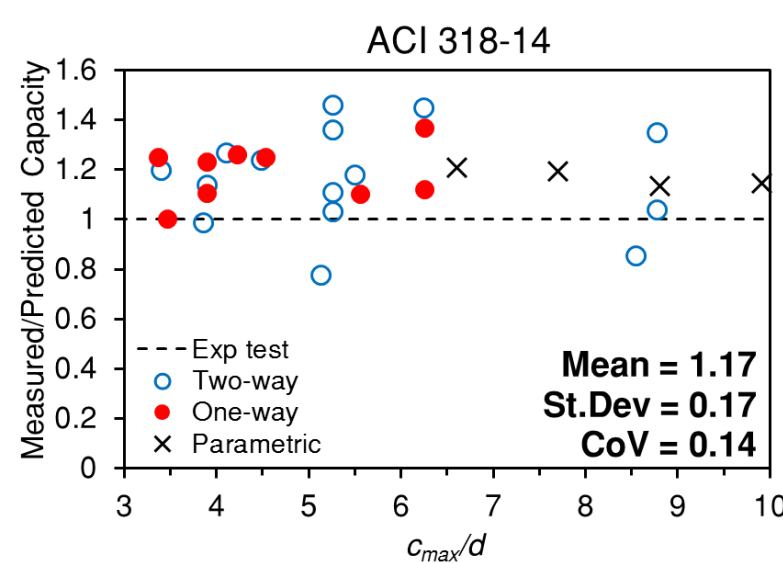

(a)

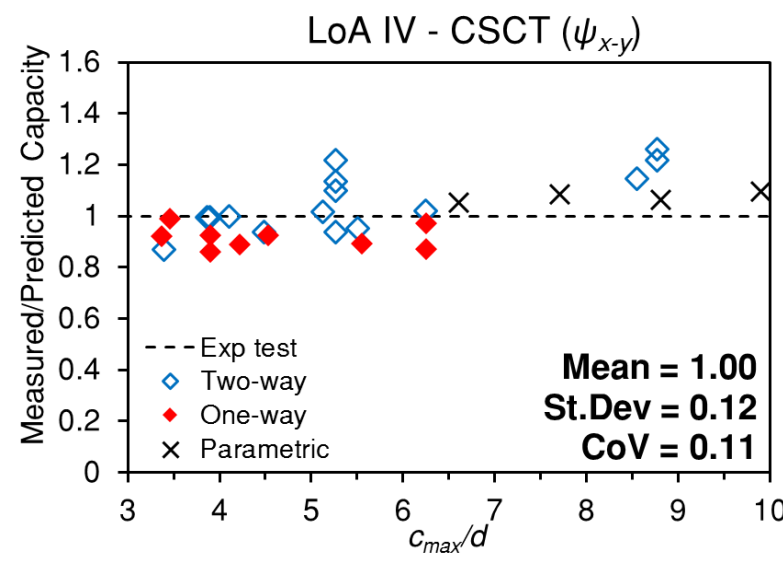

(d)

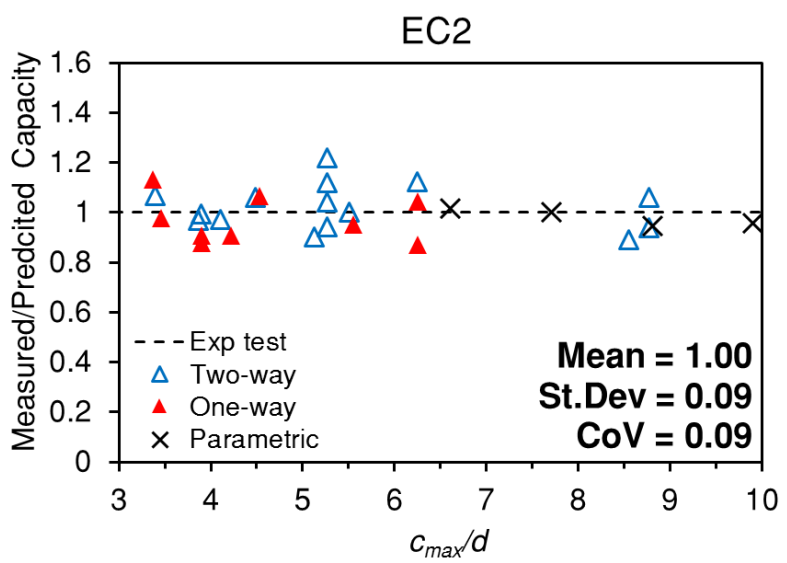

(b)

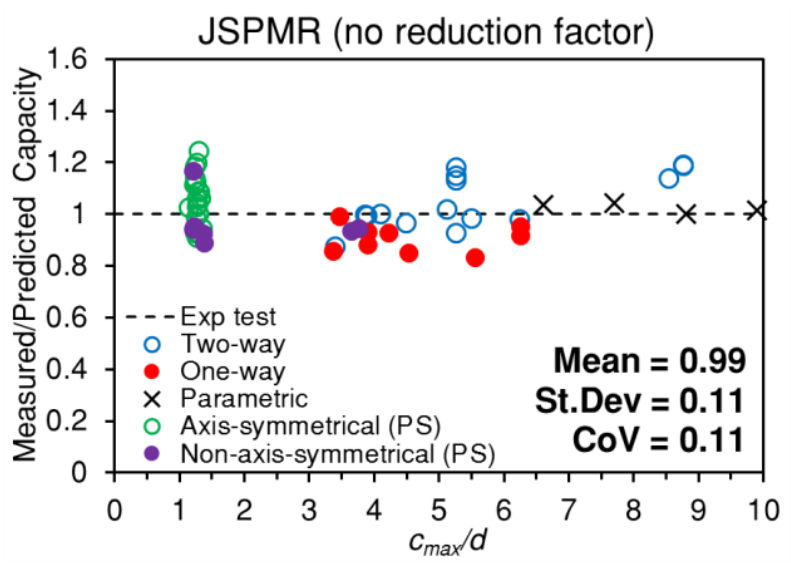

(e)

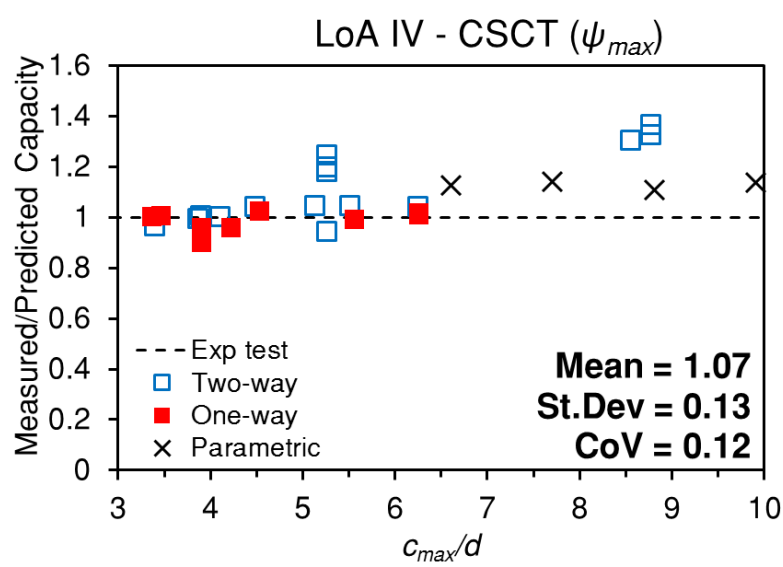

(c)

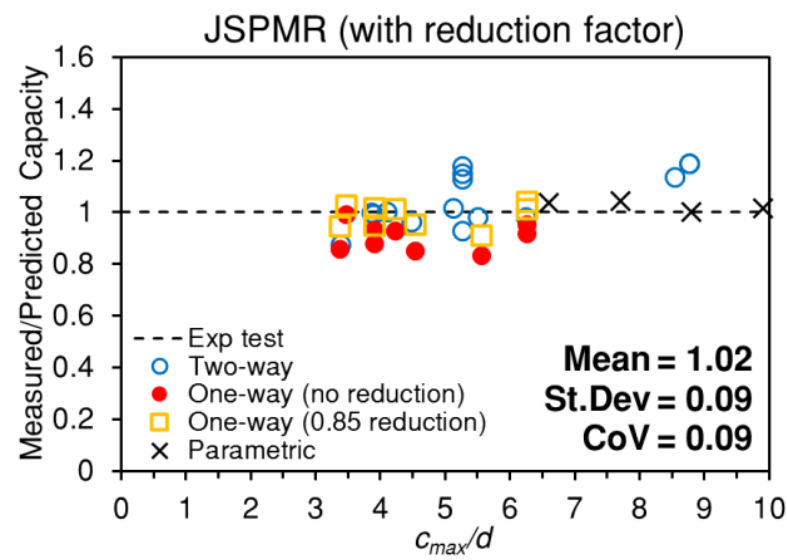

(f)

Figure 22. Measured/predicted capacity of slabs with elongated column from: (a) ACI 318-14 [4]; (b) EC2 [3]; (c) CSCT [7] ( $\psi_{\max }$ ); (d) CSCT [16] $\left(\psi_{x-y}\right)$; (e) JSPMR (no reduction factor); (f) JSPMR ( $\alpha=0.85$ for one-way loaded slabs) 
Table 3. Database of selected slab specimens with elongated column.

\begin{tabular}{|c|c|c|c|c|c|c|c|c|c|c|c|c|c|c|}
\hline No & Slab & Source & $\begin{array}{c}\text { Loading } \\
\text { configuration }\end{array}$ & $\begin{array}{c}c_{\max } \\
(\mathbf{m m})\end{array}$ & $\begin{array}{l}c_{\min } \\
(\mathbf{m m})\end{array}$ & $\begin{array}{l}c_{\max } \\
/ c_{\min }\end{array}$ & $\begin{array}{c}\text { Slab } \\
\text { thickness } \\
(\mathbf{m m})\end{array}$ & $\underset{(\mathbf{m m})}{d}$ & $\begin{array}{l}c_{\max } \\
/ d\end{array}$ & $\begin{array}{c}\boldsymbol{f}_{c}^{\prime} \\
(\mathbf{M P a})\end{array}$ & $\begin{array}{c}d_{g} \\
(\mathbf{m m})\end{array}$ & $\begin{array}{c}\boldsymbol{f}_{\boldsymbol{y}} \\
(\mathbf{M p a})\end{array}$ & $\rho_{x}$ & $\rho_{y}$ \\
\hline 1 & 2 & \multirow{6}{*}{ Hawkins et al. [35] } & Type A & 406.4 & 203.2 & 2.00 & 152 & 117 & 3.46 & 28.06 & 19 & 411 & 1.2 & 1.04 \\
\hline 2 & 3 & & Type A & 457.2 & 152.4 & 3.00 & 152 & 117 & 3.90 & 29.92 & 19 & 411 & 1.2 & 1.04 \\
\hline 3 & 4 & & Type A & 495.3 & 114.3 & 4.33 & 152 & 117 & 4.22 & 29.3 & 19 & 411 & 1.2 & 1.04 \\
\hline 4 & 5 & & Type A & 457.2 & 152.4 & 3.00 & 152 & 117 & 3.90 & 27.44 & 19 & 411 & 1.672 & 1.595 \\
\hline 5 & 7 & & Type D & 457.2 & 152.4 & 3.00 & 152 & 117 & 3.90 & 26.06 & 19 & 411 & 0.934 & 0.815 \\
\hline 6 & 8 & & Type D & 495.3 & 114.3 & 4.33 & 152 & 121 & 4.11 & 24.68 & 19 & 414 & 0.872 & 0.783 \\
\hline 7 & Slab 1 & \multirow{3}{*}{$\begin{array}{l}\text { Al-Yousif and } \\
\text { Regan [36] }\end{array}$} & Type A & 500 & 100 & 5.00 & 100 & 80 & 6.25 & 26.3 & 10 & 472 & 1.04 & 0.92 \\
\hline 8 & Slab 2 & & Type C & 500 & 100 & 5.00 & 100 & 80 & 6.25 & 25.8 & 10 & 472 & 1.04 & 0.92 \\
\hline 9 & Slab 3 & & Type B & 500 & 100 & 5.00 & 100 & 80 & 6.25 & 23.7 & 10 & 472 & 0.92 & 1.04 \\
\hline 10 & $\mathrm{~L} 3 \mathrm{~b}$ & \multirow{6}{*}{ Oliveira et al. [1] } & Type B & 360 & 120 & 3.00 & 130 & 107 & 3.36 & 60 & 16 & 749 & 1.06 & 1.03 \\
\hline 11 & L3c & & Type C & 360 & 120 & 3.00 & 130 & 106 & 3.40 & 54 & 16 & 749 & 1.06 & 1.03 \\
\hline 12 & $\mathrm{~L} 4 \mathrm{~b}$ & & Type B & 480 & 120 & 4.00 & 130 & 106 & 4.53 & 54 & 16 & 749 & 1.06 & 1.03 \\
\hline 13 & $\mathrm{~L} 4 \mathrm{c}$ & & Type C & 480 & 120 & 4.00 & 130 & 107 & 4.49 & 56 & 16 & 749 & 1.06 & 1.03 \\
\hline 14 & $\mathrm{~L} 5 \mathrm{~b}$ & & Type B & 600 & 120 & 5.00 & 130 & 108 & 5.56 & 67 & 16 & 749 & 1.06 & 1.03 \\
\hline 15 & L5c & & Type C & 600 & 120 & 5.00 & 130 & 109 & 5.50 & 63 & 16 & 749 & 1.06 & 1.03 \\
\hline
\end{tabular}




\begin{tabular}{|c|c|c|c|c|c|c|c|c|c|c|c|c|c|c|}
\hline No & Slab & Source & $\begin{array}{c}\text { Loading } \\
\text { configuration }\end{array}$ & $\begin{array}{l}c_{\max } \\
(\mathbf{m m})\end{array}$ & $\begin{array}{l}\boldsymbol{c}_{\min } \\
(\mathbf{m m})\end{array}$ & $\begin{array}{l}c_{\max } \\
/ c_{\min }\end{array}$ & $\begin{array}{c}\text { Slab } \\
\text { thickness } \\
(\mathbf{m m})\end{array}$ & $\begin{array}{c}d \\
(\mathbf{m m})\end{array}$ & $\begin{array}{l}c_{\max } \\
/ d\end{array}$ & $\begin{array}{c}\boldsymbol{f}_{c}^{\prime} \\
(\mathbf{M P a})\end{array}$ & $\begin{array}{c}d_{g} \\
(\mathbf{m m})\end{array}$ & $\begin{array}{c}\boldsymbol{f}_{y} \\
(\mathbf{M p a})\end{array}$ & $\rho_{x}$ & $\rho_{y}$ \\
\hline 16 & OC13 & \multirow{4}{*}{ Teng et al. [10] } & Type C & 600 & 200 & 3.00 & 150 & 114 & 5.26 & 35.81 & 20 & 452.5 & 1.47 & 1.47 \\
\hline 17 & OC13-1.6 & & Type D & 600 & 200 & 3.00 & 150 & 114 & 5.26 & 32.98 & 20 & 452.5 & 1.47 & 1.47 \\
\hline 18 & OC13-0.63 & & Type D & 600 & 200 & 3.00 & 150 & 114 & 5.26 & 39.71 & 20 & 452.5 & 1.47 & 1.47 \\
\hline 19 & OC15 & & Type C & 1000 & 200 & 5.00 & 150 & 114 & 8.77 & 40.15 & 20 & 452.5 & 1.47 & 1.47 \\
\hline 20 & AM04 & Sagaseta et al. [2] & Type C & 780 & 260 & 3.00 & 250 & 202 & 3.86 & 44.6 & 16 & 516 & 0.766 & 0.829 \\
\hline 21 & S13-090 & \multirow{4}{*}{ Teng et al. [37] } & Type C & 600 & 200 & 3.00 & 150 & 117 & 5.13 & 114 & $20 *$ & 537 & 0.961 & 0.961 \\
\hline 22 & S13-143 & & Type C & 600 & 200 & 3.00 & 150 & 114 & 5.26 & 114 & $20 *$ & 501 & 1.495 & 1.495 \\
\hline 23 & S15-090 & & Type C & 1000 & 200 & 5.00 & 150 & 117 & 8.55 & 97 & $20 *$ & 537 & 0.961 & 0.961 \\
\hline 24 & S15-143 & & Type C & 1000 & 200 & 5.00 & 150 & 114 & 8.77 & 97 & $20 *$ & 501 & 1.495 & 1.495 \\
\hline
\end{tabular}

Notes: * indicates slabs with high-strength concrete where $d_{g}$ for punching and one-way shear calculation is reduced as a function of $f_{c}^{\prime}$ as proposed by Cavagnis et al. [34] 
Table 4. Predictions of punching capacity obtained with various approaches.

\begin{tabular}{|c|c|c|c|c|c|c|c|}
\hline \multirow[b]{2}{*}{ No } & \multirow[b]{2}{*}{ Specimen } & \multirow[b]{2}{*}{ Source } & \multicolumn{5}{|c|}{$V_{\text {measured }} / V_{\text {predicted }}$} \\
\hline & & & $\begin{array}{c}\text { ACI 318- } \\
14 \\
\end{array}$ & $\begin{array}{c}\text { EC } \\
2 \\
\end{array}$ & $\begin{array}{l}\text { CSCT } \\
\psi_{\max }\end{array}$ & $\begin{array}{r}\text { CSCT } \\
\psi_{x-y}\end{array}$ & $\begin{array}{c}\text { Refined joint } \\
\text { model (JSPMR) }\end{array}$ \\
\hline 1 & 2 & \multirow{6}{*}{$\begin{array}{l}\text { Hawkins et al. } \\
{[35]}\end{array}$} & 1.00 & 0.98 & 1.01 & 0.99 & $0.99 / 1.03^{*}$ \\
\hline 2 & 3 & & 1.11 & 0.91 & 0.90 & 0.86 & $0.88 / 0.95^{*}$ \\
\hline 3 & 4 & & 1.26 & 0.91 & 0.96 & 0.89 & $0.93 / 1.01^{*}$ \\
\hline 4 & 5 & & 1.23 & 0.88 & 0.96 & 0.92 & $0.93 / 1.02^{*}$ \\
\hline 5 & 7 & & 1.14 & 0.99 & 1.01 & 1.00 & 0.99 \\
\hline 6 & 8 & & 1.27 & 0.97 & 1.00 & 1.00 & 1.00 \\
\hline 7 & Slab 1 & \multirow{3}{*}{$\begin{array}{l}\text { Al-Yousif and } \\
\text { Regan [36] }\end{array}$} & 1.12 & 0.87 & 1.01 & 0.87 & $0.95 / 1.04^{*}$ \\
\hline 8 & Slab 2 & & 1.45 & 1.12 & 1.04 & 1.02 & 0.98 \\
\hline 9 & Slab 3 & & 1.37 & 1.04 & 1.02 & 0.97 & $0.92 / 1.02^{*}$ \\
\hline 10 & L3b & \multirow{6}{*}{ Oliveira et al. [1] } & 1.25 & 1.13 & 1.00 & 0.92 & $0.86 / 0.95^{*}$ \\
\hline 11 & $\mathrm{~L} 3 \mathrm{c}$ & & 1.20 & 1.07 & 0.97 & 0.87 & 0.88 \\
\hline 12 & $\mathrm{~L} 4 \mathrm{~b}$ & & 1.25 & 1.07 & 1.03 & 0.93 & $0.85 / 0.95^{*}$ \\
\hline 13 & $\mathrm{~L} 4 \mathrm{c}$ & & 1.24 & 1.06 & 1.04 & 0.94 & 0.96 \\
\hline 14 & $\mathrm{~L} 5 \mathrm{~b}$ & & 1.10 & 0.95 & 1.00 & 0.89 & $0.83 / 0.91^{*}$ \\
\hline 15 & L5c & & 1.18 & 1.00 & 1.05 & 0.95 & 0.98 \\
\hline 16 & OC13 & \multirow{4}{*}{ Teng et al. [10] } & 1.46 & 1.22 & 1.25 & 1.22 & 1.18 \\
\hline 17 & OC13-1.6 & & 1.36 & 1.12 & 1.20 & 1.10 & 1.13 \\
\hline 18 & $\begin{array}{c}\text { OC13- } \\
0.63\end{array}$ & & 1.11 & 0.94 & 0.94 & 0.94 & 0.93 \\
\hline 19 & OC15 & & 1.35 & 1.06 & 1.33 & 1.26 & 1.19 \\
\hline 20 & AM04 & $\begin{array}{c}\text { Sagaseta et al. } \\
{[2]}\end{array}$ & 0.99 & 0.97 & 1.00 & 0.99 & 1.00 \\
\hline 21 & S13-090 & \multirow{4}{*}{ Teng et al. [37] } & 0.78 & 0.90 & 1.05 & 1.02 & 1.02 \\
\hline 22 & S13-143 & & 1.03 & 1.04 & 1.18 & 1.13 & 1.15 \\
\hline 23 & S15-090 & & 0.85 & 0.89 & 1.30 & 1.14 & 1.14 \\
\hline 24 & S15-143 & & 1.04 & 0.94 & 1.37 & 1.22 & 1.19 \\
\hline & & Mean & 1.17 & 1.00 & 1.07 & 1.00 & $0.99 / 1.02^{*}$ \\
\hline & & $\begin{array}{l}\text { Standard } \\
\text { deviation }\end{array}$ & 0.17 & 0.09 & 0.13 & 0.12 & $0.11 / 0.09^{*}$ \\
\hline & & $\mathrm{CoV}$ & 0.14 & 0.09 & 0.12 & 0.11 & $0.11 / 0.09^{*}$ \\
\hline
\end{tabular}

Notes: * indicates slabs subjected to one-way loading that were reanalysed using a reduction factor $\alpha$ of 0.85

\section{Conclusions}

This paper investigates the influence of elongated supports on the punching resistance of slabs without transverse reinforcement. The main conclusions are as follows:

1. NLFEA with 3-D solid elements shows that punching failure initiates around the corners of elongated supports, and that peak resistance is reached prior to full mobilisation of shear resistance around the complete control perimeter. Consideration of the variation in shear force per unit length and the ratio of 
tangential to radial concrete strain around the punching control perimeter suggests that there is a transition in shear resistance from punching to linear at a distance of around $1.5 \mathrm{~d}$ from the corner of supports beyond which the ratio of tangential to radial strain reduces.

2. Significant shear redistribution of the type identified by Sagaseta et al. [16] was found to occur near punching failure of slabs supported on elongated supports. The ATENA analysis overestimated the degree of shear redistribution to the longer sides of the control perimeter at failure. To circumvent this, it is proposed that punching failure occurs when the radial compressive strain in the slab soffit first drops to zero at a distance of $0.5 d$ from the column face.

3. A parametric study on notionally identical slabs with increasing support length shows that the contribution of linear shear to peak resistance increases linearly with support length, reaching $13.4 \%$ at $c_{\max } / d=10$, but can be neglected for $c_{\max } / d \leq 6$. Consequently, the MC2010 approach of neglecting the contribution of one-way shear becomes increasingly conservative as $c_{\max } / d$ increases above 6 .

4. NLFEA showed the punching resistance of concentrically loaded slabs supported on elongated plates to be similar to that of slabs with fully clamped supports. This suggests that the laboratory practice of simulating elongated supports in punching tests with steel plates rather than columns is reasonable despite uplift occurring in the central region of elongated plates.

5. Refinements are made to a joint model, depicted JSPM, previously proposed by the authors [6] for modelling punching in slabs meshed with nonlinear shell elements. In this model, punching failure is simulated using discrete joint elements, incorporating the failure criterion of the CSCT [7], positioned around a rectangular control perimeter at $0.5 d$ from the column face. The advantage of JSPM over conventional implementations of the CSCT is that no post processing of results is required. Consequently, the procedure is suitable for analysis of multistorey flat slab buildings both at the design ultimate limit state and for assessment of progressive collapse scenarios. Based on the NLFEA with 3-D solid elements, a refinement (depicted JSPMR) is proposed to the JSPM for slabs with elongated supports. In this approach, one way joints are used to model the contribution of linear shear which becomes progressively more significant for $c_{\max } / d>6$. The proposed model is shown to produce reasonably accurate and consistent results for $c_{\max } / d$ ranging from 3 to 10 . For $c_{\max } / d>10$, it is suggested that shear redistribution should be limited around the control perimeter as described above. However, further experimental studies are required to validate this suggestion.

6. As well as including the contribution of one-way shear, the JSPMR has the added advantage of being widely applicable to the calculation of punching resistance without the need for obscure rules. Furthermore, unlike simplified codified design rules, it also gives useful phenomenological insights into the influence of shear redistribution on punching resistance.

7. The conclusions of this research are pertinent to design using the current draft revision to EC2 [8], due for release in 2023, which adopts a closed-form formulation of the CSCT [7]. 


\section{Acknowledgements}

The work presented in this article was supported by the Indonesia Endowment Fund for Education (LPDP). The opinions and conclusions in this document are those of the authors, and do not necessarily represent those of the sponsors.

\section{References}

[1] Oliveira, D. R. C., Regan, P. E. \& Melo, G. S. S. A., 2004. Punching resistance of RC slabs with rectangular columns. Magazine of Concrete Research, (3), pp. 123-138.

[2] Sagaseta, J., Tassinari, L., Ruiz, M. F. \& Muttoni, A., 2014. Punching of flat slabs supported on rectangular columns. Engineering Structures, 77, pp. 17-33.

[3] BSI, 2004. BS EN 1992-1-1:2004: Eurocode 2, design of concrete structures - part 1-1: general rules and rules for buildings. BSI, London, UK.

[4] ACI Committee 318, 2014. ACI Building Code Requirements for Structural Concrete (ACI 318-14) and Commentary (ACI 318R-14). American Concrete Institute, Farmington Hills, MI, 519 pp.

[5] fib (Fédération International du Béton), 2013. fib Model Code for concrete structures 2010. Fédération International du Béton, Lausanne, Switzerland.

[6] Setiawan, A., Vollum, R.L., Macorini, L., Izzuddin, B.A., 2019. Efficient 3-D modelling of punching shear failure at slab-column connections by means of nonlinear joint elements. Engineering Structures, 197, https://doi.org/10.1016/j.engstruct.2019.109372.

[7] Muttoni, A., 2008. Punching Shear Strength of Reinforced Concrete Slabs without Transverse Reinforcement, ACI Structural Journal, V. 105, No. 4, pp. 440-450.

[8] Final version of PT1-draftprEN 1992-1-1:2018 D3 Eurocode 2: Design of concrete structures -Part 11: General rules, rules for buildings, bridges and civil engineering structures Committee paper CEN/TC 250/SC 2 N 1538 - aka 'D3' (2018).

[9] Cervenka, V., Jendele, L. \& Cervenka, J., 2018. ATENA Program Documentation, Part 1, Theory. Cervenka Consulting, Prague, 334 pp.

[10] Teng, S., Cheong, H.K., Kuang, K.L., Geng, J.Z., 2004. Punching shear strength of slabs with openings and supported on rectangular columns. ACI Struct Journal 2004;101(5):678-87.

[11] Menetrey, P. and Willam, K.J., 1995. Triaxial failure criterion for concrete and its generalization. ACI Structural Journal, 92(3), pp. 311-318.

[12] Vecchio, F. J., and Collins, M. P., 1986. The modified compression-field theory for reinforced concrete elements subjected to shear. ACI Structural Journal, 83(2), 219-231.

[13] Van Mier J. G. M., 1986. Multi-axial Strain-softening of Concrete, Part I: fracture, Materials and Structures, RILEM, 19(111).

[14] Setiawan, A., Vollum, R.L., Macorini, L., 2019. Numerical and analytical investigation of internal slab-column connections subject to cyclic loading. Engineering Structures, 184, pp. 535-554.

[15] Guandalini, S., Burdet, O. L. \& Muttoni, A., 2009. Punching tests of slabs with low reinforcement ratios. ACI Structural Journal, 106(1), pp.87-95.

[16] Sagaseta, J., Muttoni, A., Ruiz, M. F. \& Tassinari, L., 2011. Non-axis-symmetrical punching shear around internal columns of RC slabs without transverse reinforcement. Magazine of Concrete Research, 63(6), pp.441-457.

[17] Setiawan, A. 2019. Efficient strategy for modelling punching failure in flat slabs. $\mathrm{PhD}$ thesis. Imperial College London.

[18] M.A.N. Hendriks, A. de Boer, B. Belletti, "Guidelines for Nonlinear Finite Element Analysis of Concrete Structures”, Rijkswaterstaat Centre for Infrastructure, Report RTD:1016-1:2017, 2017.

[19] Genikomsou, A. S. and Polak, M. A., 2015. Finite element analysis of punching shear of concrete slabs using damaged plasticity model in ABAQUS. Engineering Structures, 98, pp.38-48.

[20] Ferreira, M. P., Melo, G. S. S. A., Regan, P. E., Vollum, R. L. 2014. Punching of reinforced concrete flat slabs with double-headed shear reinforcement. ACI Structural Journal, 111(2): pp. 363-374. 
[21] Broms, C.E., 2016. Tangential strain theory for punching failure of flat slabs, ACI Structural Journal, V. 113, No. 1, pp. 95-104.

[22] Hallgren, M., 1996. Punching shear capacity of reinforced high strength concrete slabs. $\mathrm{PhD}$ thesis, Bulletin 23, Department of Structural Engineering, Royal Institute of Technology, Stockholm, Sweden, $206 \mathrm{pp}$.

[23] Milligan, G. J. and Polak, M. A., Finite element analysis of shear behaviour of concrete slabs partially supported on walls. Concrete innovations in materials, design and structures: proceedings of the 2019 fib symposium, held in Krakow, Poland, May 27-29, 2019.

[24] Shu, J., Belletti, B., Muttoni, A., Scolari, M. \& Plos, M., 2017. Internal force distribution in RC slabs subjected to punching shear. Engineering Structures, 153, pp.766-781.

[25] Setiawan A., Vollum R.L., Macorini L., Izzuddin B.A., 2020. Punching shear design of RC flat slabs supported on wall corners. Structural Concrete, DOI: 10.1002/suco.201900514.

[26] Filatov, V., Experimental investigation of stress-strain conditions in punching zone of flat slabs. Proceedings of MATEC Web Conf. 11700045 (2017). DOI: 10.1051/matecconf/201711700045.

[27] Soares, L. F. S. and Vollum, R.L., 2015. Comparison of punching shear requirements in BS8110, EC2 and MC2010. Magazine of Concrete Research 67(24): 1315-1328.

[28] Fernández Ruiz, M., Mirzaei, Y. \& Muttoni, A., 2013. Post-punching behavior of flat slabs. ACI Structural Journal, 110(5), pp.801-811.

[29] Izzuddin, B. A., Nonlinear Dynamic Analysis of Framed Structures, Thesis submitted for the degree of doctor of philosophy in the University of London, Department of Civil Engineering, Imperial College, London, 1991.

[30] Izzuddin, B.A., Tao, X.Y. \& Elghazouli, A.Y., 2004. Realistic Modeling of Composite and Reinforced Concrete Floor Slabs under Extreme Loading. Part I: Analytical Method. Journal of Structural Engineering, 130(12), pp.1972-1984.

[31] Soares LFS, 2017, Influence of slab continuity on punching resistance, $\mathrm{PhD}$ thesis. Imperial College London. https://doi.org/10.25560/48011

[32] Vollum, R.L. and Tay U.L., "Modelling tension stiffening in reinforced concrete with NLFEA", Concrete, 41, 1, (2007), 40-41.

[33] Izzuddin, B.A., 2016, ADAPTIC User Manual, Imperial College London, https://www.imperial.ac.uk/media/imperial-college/research-centres-and-groups/computationalstructural-mechanics/ADAPTIC Manual.pdf

[34] Cavagnis, F., Ruiz, M.F. \& Muttoni, A., 2018. A mechanical model for failures in shear of members without transverse reinforcement based on development of a critical shear crack. Engineering Structures, 157, pp.300-315.

[35] Hawkins, N.M., Falssen, H.B., Hinojosa, R.C. Influence of column rectangularity on the behaviour of flat plate structures. ACI Special Publication, 1971;SP-30:127-46.

[36] Al-Yousif, A.T., Regan, P.E. Punching resistances of RC slabs supported by large and/or elongated columns. Struct Eng 2003;81(5):30-4.

[37] Teng, S., Chanthabouala, K., Lim, D.T.Y., Hidayat, R., Punching Shear Strength of Slabs and Influence of Low Reinforcement Ratio. ACI Structural Journal, V. 115, No. 1, pp. 139-150. 